\title{
Collaborative Multidepot Petrol Station Replenishment Problem with Multicompartments and Time Window Assignment
}

\author{
Guangcan Xu $\mathbb{D},{ }^{1}$ Maozeng Xu $\mathbb{D},{ }^{1}$ Yong Wang $\mathbb{D},{ }^{1}$ Yong Liu $\mathbb{D},{ }^{1}$ and Qiguang $\mathrm{Lv} \mathbb{D}^{2}$ \\ ${ }^{1}$ School of Economics and Management, Chongqing Jiaotong University, Chongqing 400074, China \\ ${ }^{2}$ School of Business Administration, Chongqing University of Science \& Technology, Chongqing 401331, China \\ Correspondence should be addressed to Maozeng Xu; xmzzrxhy@cqjtu.edu.cn and Yong Wang; yongwx6@gmail.com
}

Received 26 May 2020; Revised 8 September 2020; Accepted 30 September 2020; Published 23 October 2020

Academic Editor: Eneko Osaba

Copyright ( $\odot 2020$ Guangcan Xu et al. This is an open access article distributed under the Creative Commons Attribution License, which permits unrestricted use, distribution, and reproduction in any medium, provided the original work is properly cited.

Energy supply is an important system that affects the overall efficiency of urban transportation. To improve the system operational efficiency and reduce costs, we formulate and solve a collaborative multidepot petrol station replenishment problem with multicompartments and time window assignment by establishing a mixed-integer linear programming model. The hybrid heuristic algorithm composed of genetic algorithm and particle swarm optimization is used as a solution, and then the Shapley value method is applied to analyze the profit allocation of each petrol depot under different coalitions. The optimal membership sequence of the cooperation is determined according to the strict monotone path. To analyze and verify the effectiveness of the proposed method, a regional petrol supply network in Chongqing city in China is investigated. Through cooperation between petrol depots in the supply network, the utilization of customer clustering, time window coordination, and distribution truck sharing can significantly reduce the total operation costs and improve the efficiency of urban transportation energy supply. This approach can provide theoretical support for relevant government departments and enterprises to make optimal decisions. The implementation of the joint distribution of energy can promote the sustainable development of urban transportation.

\section{Introduction}

The collaborative multidepot petrol station (PS) replenishment problem (PSRP) with multicompartments and time window assignment (CMPSRPMT) is a variant of the multidepot PSRP with time windows (MPSRPTW) [1], combining the latter with cooperation among petrol depots (PDs) and truck sharing (TS) of petrol distribution. CMPSRPMT incorporates multicompartment truck application and integrates a collaboration mechanism to design increasingly efficient petrol distribution networks, minimize aggregate operating cost, and reduce urban traffic burden. As of 2019, China has 260 million cars and 106,556 petrol stations (PSs). Responsible for the energy supply of an increasing number of cars, PSs are mainly located in urban areas and on main traffic routes. These stations make up a huge distribution network that produces considerable operating costs and negative effects on cities and the environment each day. Therefore, analyzing this distribution network and optimizing its operations are important. CMPSRPMT is a distribution network design composed of multiple petrol depots and stations. The collaboration among PDs in the distribution network and the time window assignments (TWAs) to PSs are designed to improve the operational efficiency and ensure that products are delivered to PSs on time.

Based on operational requirements, each petrol depot (PD) in the current distribution network is only responsible for specific PSs in a certain region. PDs are cut off from others, and sharing of distribution resources in a network is extremely difficult. The result is a temporal and spatial imbalance between the capacity of distribution trucks and the demand for customer service delivery, such as the idling and roundabout transport of distribution trucks. The inefficient distribution capacity and service quality of several PDs limit the efficiency of the entire distribution network. Moreover, customer demands for heterogeneous service time windows (TWS) require depots to increase their 
number of delivery trucks, which exert pressure on transportation facilities and depot budgets. Therefore, multidepot cooperative distribution must be based on TWS and distribution TS to effectively assign customer service. Through comprehensive resource sharing, multidepot cooperative distribution reduces costs and improves the service quality of the entire distribution network. Indeed, in China, large oil companies are already collaborating on the distribution of refined products $[2,3]$. In terms of academic research, some scholars $[4,5]$ have also discussed the cooperation between different gas stations in petrol distribution.

In this study, multicompartment truck sharing, TWS, and a cooperation mechanism are integrated into the traditional MPSRPTW as CMPSRPMT. To optimize the CMPSRPMT and improve calculation accuracy, an optimal mathematical model is established to minimize the total operating cost. A hybrid heuristic algorithm that combines genetic algorithm (GA) with particle swarm optimization (PSO) algorithm is designed to achieve near-optimal solution. The Shapley value method is applied to allocate the benefits from cooperation. The membership sequence is analyzed according to the strict monotone path (SMP) principle. Therefore, it is conducive that the solution of the CMPSRPMT can improve the efficiency and flexibility of petrol distribution networks. For the CMPSRPMT, first of all, refined products have special distribution nature, that is, product diversification, and cannot be mixed; Secondly, multidepot cooperation, multicompartment vehicle use, and different time-window coordination mechanisms are comprehensively considered; it can propel the sustainable development of distribution theory and the entire intelligent urban transportation system.

The remaining parts of this study are organized as follows. In Section 2, relevant studies on petrol distribution optimization with the cooperation strategy and TWS are reviewed. In Section 3, a practical example of the CMPSRPMT is presented, and a mathematical model is established using notations and definitions to minimize total operating costs. InSection 4, a hybrid optimization methodology is introduced to solve the CMPSRPMT. In Section 5, a small-scale example and a case study in Chongqing city in China are conducted to verify the applicability of our proposed methodology. InSection 6, the conclusions and future directions are provided.

\section{Literature Review}

Past decades have scant academic research on the replenishment of PSs. Previous studies focus on optimizing the distribution of a single PD to multiple PSs and several variations of PSRP. For example, the multiperiod, time window, trip packing, and multidepots with TWS are separately considered for the PSRP $[1,6-8]$, which with its related problems receives increasing research focus given its practical importance. Popović et al. [9] developed a variable neighborhood search heuristic for solving a multiproduct, multiperiod inventory routing problem (IRP) in fuel delivery with multicompartment homogenous vehicles. Their method was proven superior to other optimization methods.
Vidović et al. [10] proposed a mixed-integer programming model and a heuristic approach with and without fleet size costs to observe their impact on the multiproduct, multiperiod IRP in fuel delivery. Huang [11] employed the tabu search to solve an advanced capacitated location-routing problem in a distribution network with multiple pickup and delivery routes. Wang et al. [12] formulated an oil distribution model intra-area with distribution quantity and routing as decision variables to extend the multidepot half open vehicle-routing problem with TWS. They also used GA to solve this model. Carotenuto et al. [13] provided a mathematical formulation to the periodic PSRP and proposed different heuristic solutions. Wang et al. [14] proposed a mathematical model that considered petrol trucks returning to a depot multiple times and developed a heuristic algorithm according to a local branch-and-bound search with a tabu list and the Metropolis acceptance criterion to solve it.

The aforementioned works are some of the few that are directly related to PSRP modeling and research. However, the present study is closely related to the multicompartment truck transportation and TS to be considered in modeling. Derigs et al. [15] introduced a formal model, an integer program formulation, and a benchmark suit of 200 instances of a general vehicle-routing problem with compartments and presented a solver suite of heuristic components. He et al. [16] likewise investigated an approach that can be used in sharing internal trucks among multiple container terminals (SIMT) and proposed a novel strategy to resolve the SIMT problem for a specific large port with multiple adjacent container terminals. Lahyani et al. [17] optimized a rich multiproduct, multiperiod, and multicompartment vehicle routing of the olive oil collection process in Tunisia using a mathematical formulation, specifically an exact branch-andcut algorithm. Coelho and Laporte [18] defined and compared four main categories of the multicompartment delivery problem (MCDP). They proposed formulations and models for certain MCDP cases and versions and then described a branch-and-cut algorithm that is applicable to all variants. Ostermeier and Hübner [19] identified vehicledependent costs within empirical data collection and used a large neighborhood search to solve an extended multicompartment vehicle-routing problem (MCVRP) for grocery distribution. Vahdani et al. [20] developed a biobjective optimization model and used two metaheuristic multiobjective algorithms to integrate the assignment of quay cranes in container terminals and internal TS assignment.

One part of the CMPSRPMT literature focuses on the problem of cooperation in the distribution networks. Cooperation among PDs largely influences the efficiency of their distribution networks. Qi et al. [21] proposed an alternative approach based on spatiotemporal partitioning to solve a large-scale VRP with time windows (VRPTW) using a genetic algorithm developed for $K$-medoid clustering of large-scale customers. Wang et al. [22] presented an improved PSO algorithm to minimize the total cost of the multiple centers' joint distribution network when each distribution center is assigned to serve a series of distribution units. Wang et al. [23] used a mixed-integer linear 
programming model to minimize the total operating cost of nonempty coalitions of two-echelon heterogeneous cooperative logistics networks and the GA-PSO algorithm to solve customer clustering units' reallocation problem. Wang et al. [24] established a linear mathematical model to minimize the total cost of the two-echelon logistics delivery and pickup network (2E-LDPN) and solved it by combining an improved PSO algorithm with the ant colony optimization algorithm to create hybrid metaheuristics. In the above studies, different heuristics are used to solve the problem in combination with various models.

Another part of the CMPSRPMT literature focuses on the TWA in distribution. Neves-Moreira et al. [25] presented a new formulation for the time window assignment vehiclerouting problem (TWAVRP) where TWS are defined for multiple product segments. The means of a fix-and-optimize-based math-heuristic method are used to solve this two-stage stochastic optimization problem. Martins et al. [26] extended research on MCVRPS by tackling a multiperiod setting with a product-oriented TWA and proposed an adaptive large neighborhood search as the solution. Wang et al. [27] established a biobjective programming model that optimizes the total operating routing cost and the total number of delivery vehicles for a collaborative multidepot VRP with TWA (CMDVRPTWA). They solved the model using a hybrid heuristic algorithm consisting of $K$-means clustering, Clarke-Wright (CW) saving algorithm, and extended nondominated sorting genetic algorithm-II (ENSGAII).

Generally speaking, the mathematical model of vehicle assignment and routing problem is NP hard. In order to solve this kind of problem, it is very important to select and apply appropriate algorithms. Kuo et al. [28] proposed a hybrid PSO with GA (HPSOGA) for solving the capacitated VRP with fuzzy demand (CVRPFD). Azadeh et al. [29] presented a PSO algorithm synchronized with a local search heuristic and developed two other hybrid algorithms based on GA and ant colony optimization (ACO) algorithms to solve the crew scheduling problem. Zhou et al. [30] proposed two parthenogenetic algorithms (PGA) and adapted PSO and one state-ofthe-art method to solve multiple traveling salesman problems (MTSPs). Tohidifard et al. [31] used GA and PSO to solve a new mathematical model for a multidepot VRP with TWS for home health care firms. Zhang et al. [32] presented a twostage improved GA-PSO algorithm to solve the coal bed methane gathering network optimizing problem.

The aforementioned studies tackle numerous PSRP aspects but suffer from the following issues. (1) The replenishment network design procedure rarely considers the cooperation among PDs by regional partitioning. (2) Minimal attention is paid to distribution TS, multicompartment truck application, and transship transportation among the participants of a collaborative multidepot optimization network. (3) A single intelligent algorithm and heuristic approach are difficult to apply directly to a specific scale of CMPSRPMT with numerous PSs.

Combining observations in Table 1, the main contributions of this study lie in the following aspects: (1) proposing a cooperation mechanism based on the regional partitioning method and constructing a collaborative multidepot PS replenishment network with multicompartments and TWA; (2) establishing a mixed-integer linear programming model based on the minimum total operating cost and the number of multicompartment trucks for the CMPSRPMT; (3) designing a hybrid heuristic algorithm that combines GA and PSO algorithm to effectively address the optimization model; and (4) executing a real-world case study to assess the applicability of the proposed model and approach and compare the costs and benefits before and after the collaboration. In addition, this study lays a foundation and strategy for optimizing the cooperative energy supply network, which is conductive to improving the construction of the sustainable energy supply chain.

\section{Problem Statement and Model Formulation}

3.1. Problem Statement. CMPSRPMT integrates the problems of cooperative distribution, TS, and TWAs. Figure 1 illustrates a noncooperative refined products' distribution network in which PDs operate independently and serve only their own customers. As such, long-haul deliveries are inevitable. A single PD also needs a large number of delivery petrol tankers to meet different demands and time window requirements of its customers. This case results in a substantial decrease in the distribution efficiency and an increase in distribution costs. Given the numerous crosstransportations, the distribution network becomes increasingly complicated and thus vulnerable to disruptions.

Figure 2 displays an optimized refined products' distribution network with cooperation, TS, and TWAs. In this network, large tankers transfer refined products across depots. These petrol distribution trucks are responsible for refined products' delivery from each depot to each PS. This cooperation leads to a more organized and ordered distribution system than the noncooperative distribution network. The required number of petrol distribution trucks and service scope of each PD are likewise reduced.

On the basis of the regional partitioning method, the transport time between petrol depots and stations is used to cluster corresponding PSs. Different customer groups are assigned to different PD services, and the demand of an individual PS is combined with the required time window. Different types of petrol tankers are assigned to distribution on the basis of the appropriate time window for each PD.

Five assumptions underline the corresponding mathematical model. (1) In a relatively short time period, each PS only generates one distribution order for refined products' demand. The demand for each kind of refined products does not exceed the maximum loading capacity of a single compartment of the distribution truck. (2) Each customer (PS) can only be served once in a time period, but its demand can be fulfilled by multiple distribution trucks. Specifically, one PD can organize a distribution task, but multiple trucks can complete the distribution task. (3) The transportation speed of petrol transfer trucks and petrol distribution trucks is constant. (4) During a time period, distribution trucks may be dispatched repeatedly if time permits, regardless of the transfer time across PDs. (5) The loading and unloading 
TABLE 1: Comparison between the existing literature and this study.

\begin{tabular}{|c|c|c|c|c|c|c|}
\hline Study & Number of depots & Stations per trip & Time windows & Multicompartments & Fleet sharing & Regional partitioning \\
\hline Cornillier et al. [6] & One & Several & No & Yes & No & No \\
\hline Cornillier et al. [7] & One & Several & Yes & Yes & No & No \\
\hline Boctor et al. [8] & One & Several & No & No & No & No \\
\hline Cornillier et al. [1] & Several & Several & Yes & Yes & No & No \\
\hline Popović et al. [9] & One & Several & No & Yes & No & No \\
\hline Vidović et al. [10] & One & Several & No & Yes & No & No \\
\hline Wang et al. [12] & Several & Several & Yes & No & Yes & No \\
\hline Carotenuto et al. [13] & One & Several & No & Yes & No & No \\
\hline Wang et al. [14] & One & Several & Yes & Yes & No & No \\
\hline This study & Several & One & Yes & Yes & Yes & Yes \\
\hline
\end{tabular}

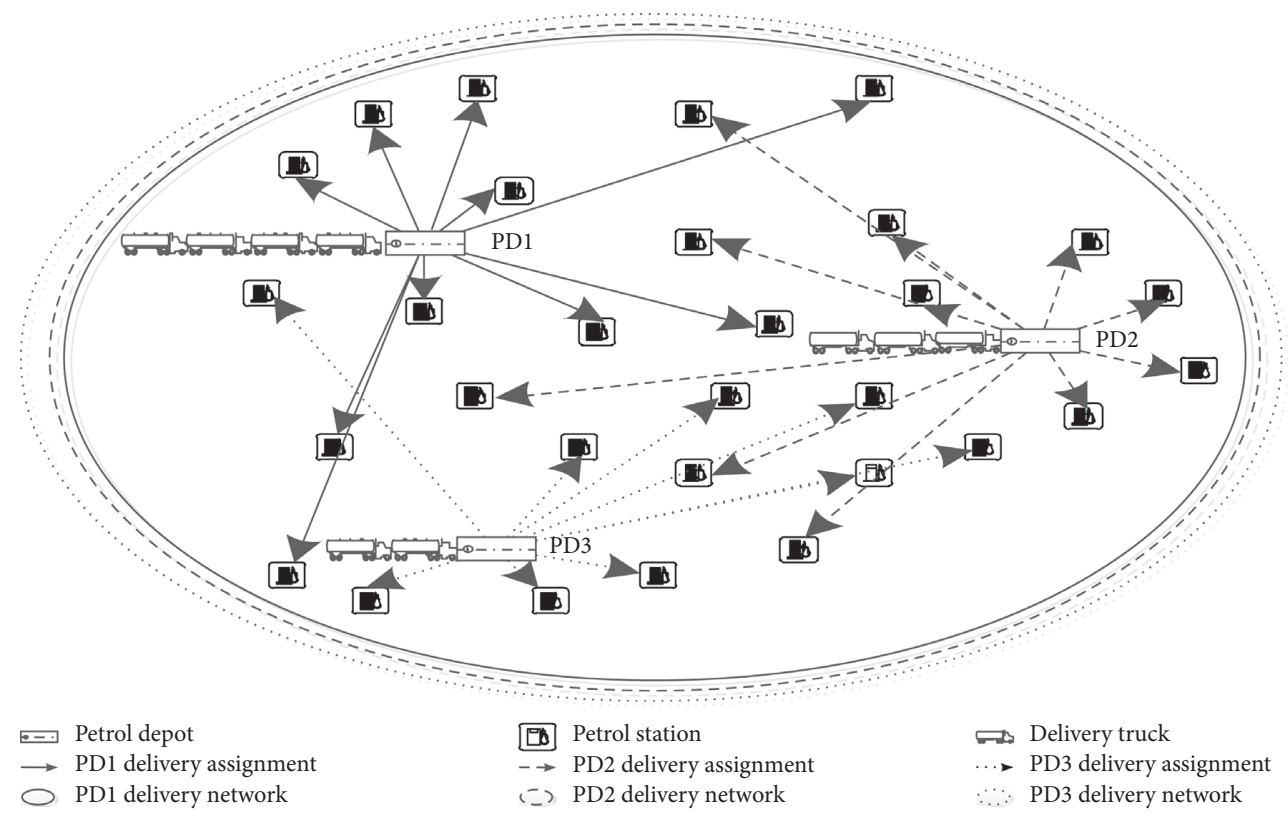

Figure 1: Noncooperative petrol distribution network.

service times of PDs and stations are related not to the refined products' type but to the truck type and operational quantity.

3.2. Model Formulation. The proposed model is mathematically formulated as an optimization problem to minimize the total cost when each PD is assigned to serve a group of PSs with different trucks and TWS [23, 27]. Table 2 lists the related notations and definitions adopted in the CMPSRPMT optimization.

CMPSRPMT is formulated as a mixed-integer linear programming model to minimize the total cost. The cost function contains three components, namely, $C_{1}, C_{2}$, and $C_{3}$, which are described as follows.

Equation (1) shows the formulation for $C_{1}$, which denotes the total transportation cost of transferring refined products across PDs and the maintenance cost of transferring petrol trucks within a working period:

$$
C_{1}=\sum_{i, p \in I, p \neq i} \sum_{k \in K}\left[\frac{F_{i p k}}{L_{o}} \times f_{o} \times\left(t_{i p}+t_{p i}\right)+\frac{F_{i p k}}{L_{o}} \times \frac{M_{o}}{T}\right] .
$$

Equation (2) shows the formulation for $C_{2}$, which denotes the total transportation cost, maintenance cost of all distribution trucks assigned to deliver different refined products from a depot to a PS during a working period, and the penalty cost for delivering trucks that arrive early or late:

$$
\begin{aligned}
C_{2}=\sum_{i \in I} \sum_{j \in J} \sum_{a \in A}\left[\begin{array}{c}
r_{i j a} \times f_{a} \times\left(t_{i j}+t_{j i}\right) \\
+\varpi_{1} \times r_{i j a} \times \max \left(e_{j}-t_{i j a}, 0\right) \\
+\Phi_{2} \times r_{i j a} \times \max \left(t_{i j a}-l_{j}, 0\right)
\end{array}\right] \\
+\sum_{a \in A} \max _{\varphi \in \phi}\{|U T a, \varphi|\} \times \frac{M_{a}}{T} .
\end{aligned}
$$

Equation (3) shows the formulation for $C_{3}$, which denotes the fixed and variable costs of petrol depots that belong to the collaborative petrol distribution network:

$$
C_{3}=\sum_{i, p \in I, i \neq p} \sum_{k \in K}\left[\left(1-W_{i}\right) \times G_{i}+W_{i} \times S_{i}+\gamma \times\left(F_{i p k}+Q_{i}\right)\right] \text {. }
$$




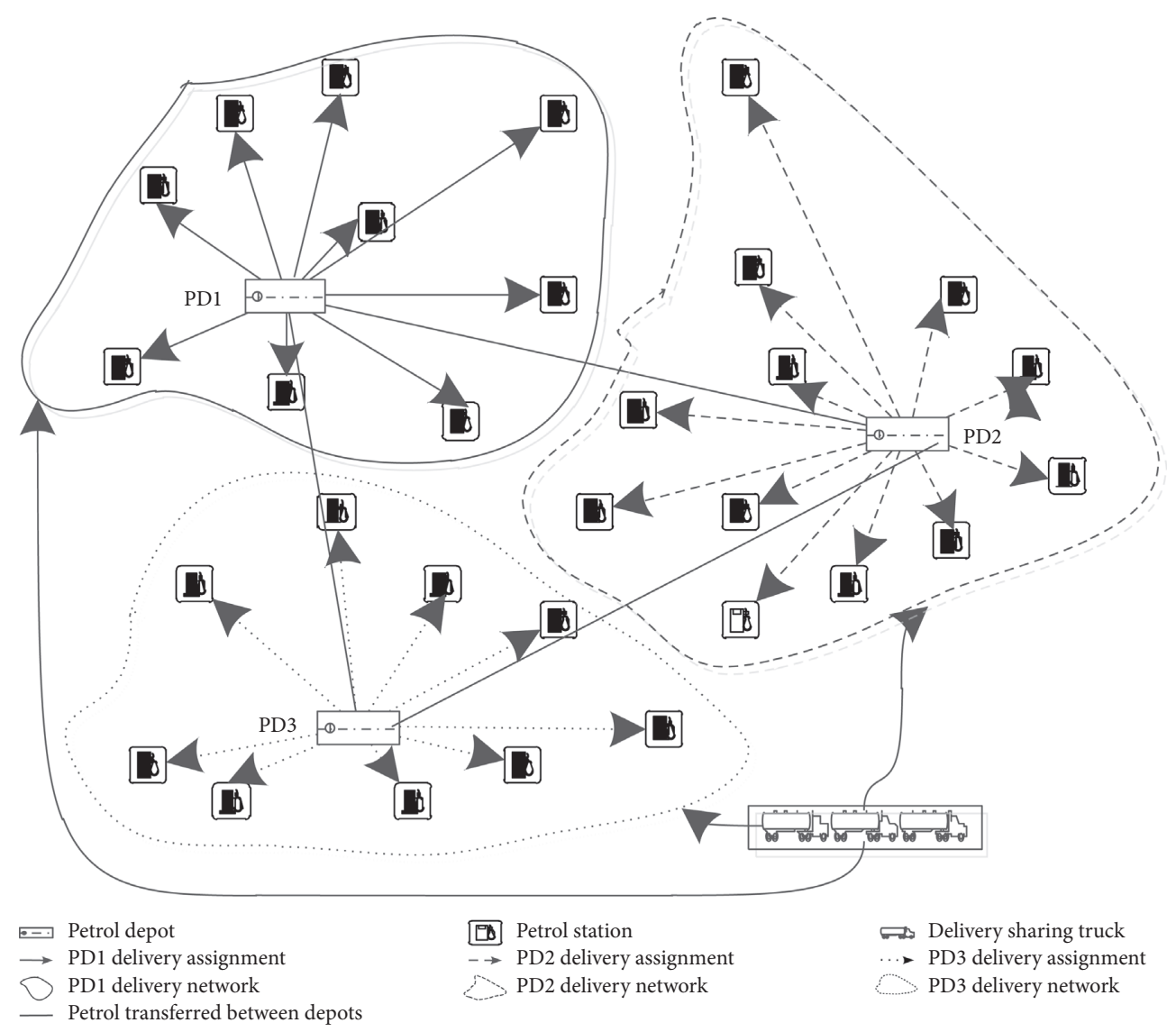

Figure 2: Cooperative petrol distribution network.

The optimization model of the CMPSRPMT is defined as follows:

$$
\min T C=C_{1}+C_{2}+C_{3},
$$

subject to

$$
\begin{aligned}
& \max \left(q_{j k}\right) \leq \max \left(Q_{a}^{h}\right), \quad \forall j \in J, k \in K, a \in A, h \in H_{a}, \\
& \sum_{a \in A} \sum_{h \in H_{a}} y_{j k}^{a h}=1, \quad \forall j \in J, k \in K, \\
& t_{L S_{j a}}=r_{i j a}\left(L S_{a} \times q_{j}\right), \quad \forall i \in I, j \in J, a \in A, \\
& t_{U S_{j a}}=r_{i j a}\left(U S_{a} \times q_{j}\right), \quad \forall i \in I, j \in J, a \in A, \\
& t_{i j a}=r_{i j a}\left(t_{i j a}^{s}+t_{i j}\right), \quad i \in I, j \in J, a \in A, \\
& t_{j i a}^{r}=r_{i j a}\left(t_{i j a}+t_{U S_{a}}+t_{i j}\right), \quad i \in I, j \in J, a \in A, \\
& W_{i} \leq 1, \quad W_{i}=\{0,1\}, \quad \forall i \in I, \\
& Q_{i}=\sum_{k \in K} Q_{i k}, \quad \forall i \in I,
\end{aligned}
$$

$$
\begin{aligned}
& q_{k}=\sum_{j \in J} q_{j k}, \quad \forall k \in K, \\
& Q=\sum_{k \in K} q_{k}=\sum_{j \in J} \sum_{k \in K} q_{j k}, \quad \forall j \in J, k \in K, \\
& r_{i j a}=r_{j i a}=\{0,1\}, \quad i \in I, j \in J, a \in A, \\
& r_{i j a}\left(1-r_{i j a}\right)=0, \quad i \in I, j \in J, a \in A, \\
& y_{j k}^{a h}\left(1-y_{j k}^{a h}\right)=0, \quad j \in J, k \in K, a \in A, h \in H_{a}, \\
& S_{i}=\lambda Q_{i}, \quad \forall i \in I .
\end{aligned}
$$

Equation (4) shows the objective function, which minimizes the total cost of the regional petrol distribution network. Constraint (5) ensures that the demand for one kind of refined products at any PS is less than or equal to the maximum capacity of a single compartment of the distribution truck. Constraint (6) guarantees that the demand for certain products in a PS can only be distributed by a certain compartment of a certain truck. Constraint (7) defines the loading service time of a certain delivery truck that distributes refined products to a certain PS. Constraint (8) defines the unloading service time of a distribution truck distributing refined products at a PS. Constraint (9) specifies 
TABLE 2: Notations and definitions in the CMPSRPMT.

\begin{tabular}{l} 
Symbol \\
\hline$I:\{i=1,2,3, \ldots, m\}$ \\
$J:\{j=1,2,3, \ldots, n\}$ \\
$O$
\end{tabular}

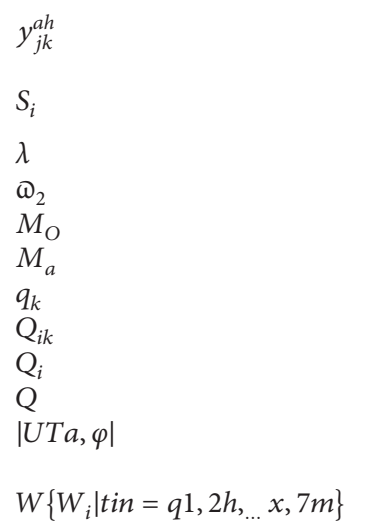

$G_{i}$

$\gamma$
$T$

$r_{i j a}$

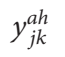

$S_{i}$

Description

Set of PDs

Set of PSs

Set of petrol transfer trucks

Set of petrol trucks, $O$ represents the petrol trucks which transfer different kinds of petrol between different PDs, and the petrol transfer truck can only be responsible for the transfer of one kind of petrol at a time; in addition, $a$ represents different types of petrol distribution trucks, and each distribution truck has a different subdivision and different capacity

Set of subdivisions of $a$-type petrol distribution truck

Represents the maximum capacity of the $h_{\mathrm{th}}$ subdivision of $a$-type petrol distribution truck, $h \in H_{a}$ Set of petrol varieties

Represents a working period

Represents one time period of a working period, $\varphi \in \phi$

The cost of time delay as the penalty coefficient when $t_{i a j}>l_{j}$

The average annual maintenance cost of the petrol transfer truck (dollar/Y)

The average annual maintenance cost of different kinds of petrol distribution truck (dollar/Y), $a \in A$

The total demand of $k$ petrol for all the PSs in a time period (gallon), $k \in K$

The distribution operating quantity of $k$ petrol for $\mathrm{PD} i$ in a time period (gallon), $i \in I, k \in K$

The total distribution operating quantity of all kinds of petrol for PD $i$ in a time period (gallon), $i \in I$

The demand quantity of all kinds of petrol for all the PSs in a time period (gallon)

The demand quantity of $a$-type petrol distribution truck in time period $\varphi, a \in A$ and $\varphi \in \phi$ Decision matrix, $W_{i}=1$ represents that the PD is willing to cooperate with other PDs in the region and joins the joint distribution network of petrol; $W_{i}=0$ represents that the PD refuses to join the regional distribution network, $i \in I$

The fixed cost of PD $i$ in a time period, $i \in I$

The variable cost factor of the $\mathrm{PD}$; it is related to the operating quantity of the $\mathrm{PD}$

The working periodicity

The relationship among PD $i$, PS $j$, and petrol distribution truck $a$ in a time period; $r_{i j a}=1$ represents that the petrol distribution truck $a$ is determined to be responsible for the petrol distribution from PD $i$ to PS $j$, and

$r_{i j a}=0$ represents that the petrol distribution truck $a$ is not selected to be responsible for the petrol distribution from PD $i$ to PS $j$; similarly, $r_{\text {jia }}=1$ represents that the petrol distribution truck $a$ returns back to $\mathrm{PD} i$ from PS $j, r_{i p a}=1$ represents that the petrol distribution truck $a$ is deployed to PD $p$ from PD $i$, versa, $i, p \in I, i \neq p, j \in J$, and $a \in A$

If the petrol $k$ demand of PS $j$ is completed by the $k_{\text {th }}$ compartment of the petrol distribution truck $a$, the value is 1 ; otherwise, it is $0, j \in J, k \in K, a \in A$, and $h \in H_{a}$

The service cost (including labor cost and operation cost) allocated on behalf of the PD participating in the petrol regional joint distribution network, and it is related to the distribution operating volume, $i \in I$ The operating volume coefficient of service cost

The cost of time delay as the penalty coefficient when $t_{i a j}>l_{j}$

The average annual maintenance cost of the petrol transfer truck (dollar/Y)

The average annual maintenance cost of different kinds of petrol distribution truck (dollar/Y), $a \in A$

The total demand of $k$ petrol for all the PSs in a time period (gallon), $k \in K$

The distribution operating quantity of $k$ petrol for PD $i$ in a time period (gallon), $i \in I$ and $k \in K$

The total distribution operating quantity of all kinds of petrol for PD $i$ in a time period (gallon), $i \in I$

The demand quantity of all kinds of petrol for all the PSs in a time period (gallon)

The demand quantity of type $a$ petrol distribution truck in time period $\varphi, a \in A$ and $\varphi \in \phi$

Decision matrix, $W_{i}=1$ represents that the PD is willing to cooperate with other PDs in the region and joins the joint distribution network of petrol; $W_{i}=0$ represents that the PD refuses to join the regional distribution network, $i \in I$

The fixed cost of PD $i$ in a time period, $i \in I$

The variable cost factor of $\mathrm{PD}$; it is related to the operating quantity of the $\mathrm{PD}$

The working periodicity

The relationship among PD $i$, PS $j$, and petrol distribution truck $a$ in a time period; $r_{i j a}=1$ represents that the petrol distribution truck $a$ is determined to be responsible for the petrol distribution from PD $i$ to PS $j$, and

$r_{i j a}=0$ represents that the petrol distribution truck $a$ is not selected to be responsible for the petrol

distribution from PD $i$ to PS $j$; similarly, $r_{j i a}=1$ represents that the petrol distribution truck $a$ returns back to PD $i$ from PS $j$, and $r_{i p a}=1$ represents that the petrol distribution truck $a$ is deployed to PD $p$ from PD $i$, versa, $i, p \in I, i \neq p, j \in J$, and $a \in A$

If the petrol $k$ demand of PS $j$ is completed by the $k_{\text {th }}$ compartment of the petrol distribution truck $a$, the value is 1 ; otherwise, it is $0, j \in J, k \in K, a \in A$, and $h \in H_{a}$

The service cost (including labor cost and operation cost) allocated on behalf of the PD participating in the petrol regional joint distribution network, and it is related to the distribution operating volume, $i \in I$ The operating volume coefficient of service cost 
the arrival time of a distribution truck to the PS to be served. Constraint (10) represents the time when a distribution truck returns to the departure depot after serving a PS. Constraint (11) indicates that a PD in the regional distribution network can either choose to join or not join the regional petrol distribution. Constraint (12) defines the total distribution capacity of different refined products of a PD in a time period. Constraint (13) represents the total demand quantity of refined product $k$ from all the PSs in a time period. Constraint (14) indicates the demand quantity of all kinds of refined products from all the PSs in a time period. Constraint (15) ensures that a distribution truck serves only one PS at a time. Constraints (16) and (17) represent the value range of variables. Constraint (18) defines the service cost allocated by a PD over a time period.

\section{Solution Methodology}

4.1. Hybrid Algorithm Solving Procedure. A GA-PSO hybrid algorithm is designed to address the petroleum distribution of the multidepot PS optimization model. GA is an evolutionary computing approach used to mimic the natural selection procedure and study combinatorial optimization problems [33]. PSO was proposed by Kennedy and Eberhart as one of the swarm intelligence stochastic evolutionary metaheuristic approaches [34]. Based on swarm theory, PSO is inspired by observations of the social behavior of bird flocking and fish schooling. This algorithm can be used to optimize local and global locations according to the particle position and velocity. Traditionally, GA and PSO have the merits of being population-based heuristics with the ability to evaluate the fitness of each possible solution. Through local and global search capabilities, GA and PSO are successfully applied to solve problems in engineering, management, and pure science domains. Given their individual abilities, GA and PSO are combined as a hybrid algorithm in this study to inherit the merits of both approaches and increase the probability of obtaining optimal solutions.

As a hybrid algorithm, GA-PSO is applied to meet the requirements of the multidepot PSRP optimization for more complex algorithms. Existing traditional heuristics are already proven efficient. However, the complexity of petrol distribution networks limits their capacity in finding nearoptimal solutions. As such, properly integrating different methods into a hybrid solution approach such as GA-PSO can effectively improve the optimization results. Other hybrid heuristics exist but may display weaknesses compared with GA-PSO in terms of performance. For example, Chen et al. [35] addressed a task assignment problem by embedding a local search heuristic into the ACO algorithm to improve the solution search ability. Their proposed methodology had a satisfying global search capability but insufficient local search. In addition, some studies [36-38] discussed the related variants of GA-PSO and its application in the centralized charging strategy of electric vehicles, multiqueue scheduling, and spatiotemporal task scheduling.
And some research studies $[39,40]$ also applied more advanced particle swarm optimization variants in the neural network, burden distribution matrix, and other aspects. Thus, combining GA and PSO ensures good performances at local and optimum search levels, improves the optimization procedure, and reduces the number of necessary iterations. The relevant operations and processes of the proposed hybrid algorithm are illustrated in the subsequent sections.

Similar to existing research $[41,42]$, Figure 3 describes the procedure of the hybrid algorithm. The details of the main steps are as follows:

Step 1: algorithm initialization: in the hybrid algorithm, the PD performs the refined products' delivery service. An integer within $\left[0, T_{o}^{\prime}\right]$ is randomly selected and assigned to the gene location of each chromosome to check whether it meets the requirements. $T_{o}^{\prime}$ represents the number of PDs set for refined products' distribution service. New chromosomes are generated until requirements are fulfilled. Formula (19) shows the calculation for the fitness function value $F_{k} . T C_{k}$ indicates the objective function of the $k$ th chromosome, $\delta_{k}$ represents the unqualified chromosome number, and $M$ denotes the penalty weight for each unqualified chromosome (particle).

$$
F_{k}=\frac{1}{\mathrm{TC}_{k}+\delta_{k} \times M} .
$$

Step 2: given the improved chromosome fitness function value, roulette wheel selection is then carried out. Crossover and mutation operations are executed based on the crossover probability $p_{c}$ and the mutation probability $p_{m}$, respectively. The optimal solutions and new chromosomes are updated.

Step 3: $E$ chromosomes are selected as the initial particles in the population to handle the PSO operations as part of the hybrid algorithm. In addition, the individual optimal solution pbest $t_{k}^{t}$ and the global optimal solution gbest $_{k}^{t}$ are calculated according to formulas (20)-(22). $V_{g}$ represents the allowable maximum velocity for the PS replenishment service. $v_{k}^{t}$ denotes the corresponding particle velocity. $c_{1}$ and $c_{2}$ are the acceleration coefficients used in PSO. rand (.) represents a random fraction between 0 and $1 . x_{k}^{t}$ indicates the position of each particle (chromosome). pbest $t_{k}^{t}$ and $g$ best ${ }_{k}^{t}$ denote the individual best position of particle $k$ at the $t$ th iteration and global best position of particle $k$ at the th iteration, respectively. fix $(\cdot)$ assures that each particle is an integer. $w_{\text {int }}$ denotes the initial inertia weight. $w_{\text {end }}$ denotes the inertia weight for $S_{\max }$, which indicates the maximum number of iterations. $t$ represents the iteration number. Formulas (20) and (21) are used to update the velocity and position for refined products' replenishment services. Formula (22) is used to obtain the inertia weight $w$. 


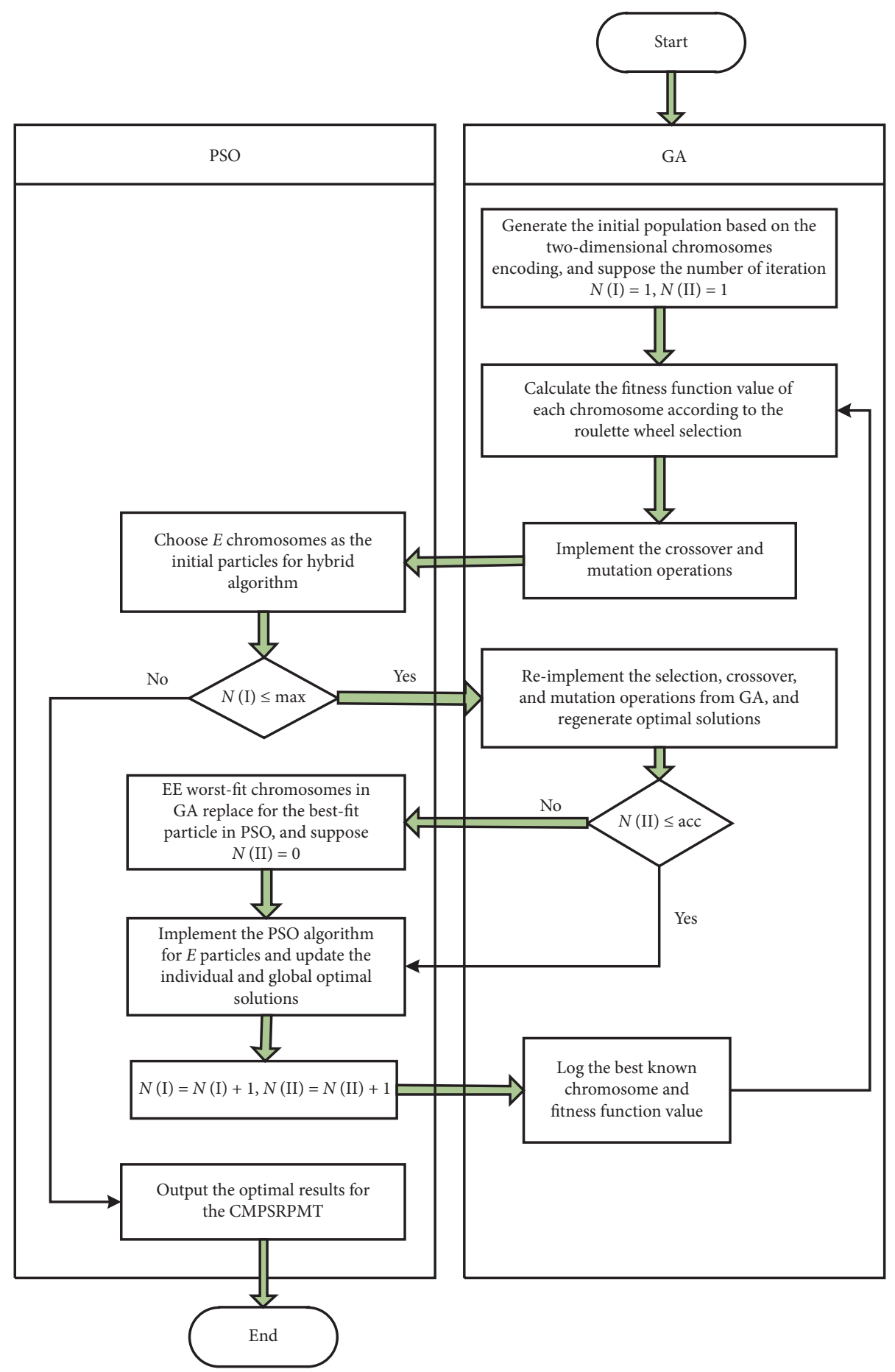

FIGURE 3: The flowchart of the hybrid algorithm.

$$
\begin{aligned}
& v_{k}^{t+1}= \begin{cases}w \times v_{k}^{t}+c_{1} \times \operatorname{rand}(t) \times\left(\text { pbest }_{k}^{t}-x_{k}^{t}\right) & -V_{g} \leq v_{k}^{t+1} \leq V_{g}, \\
+c_{2} \times \operatorname{rand}(t) \times\left(g \text { best }_{k}^{t}-x_{k}^{t}\right), & \\
-V_{g}+2 \times V_{g} \times \operatorname{rand}(t), & \text { others, }\end{cases} \\
& x_{k}^{t+1}= \begin{cases}\operatorname{fix}\left(x_{k}^{t}+v_{k}^{t+1}\right), & -V_{g} \leq x_{k}^{t+1} \leq V_{g}, \\
\text { rand int }\left[0, T_{o}^{\prime}\right], & \text { others, }\end{cases} \\
& w=\frac{\left(w_{\text {int }}-w_{\text {end }}\right) \times\left(S_{\max }-t\right)}{S_{\max }}+w_{\text {end }} \text {. }
\end{aligned}
$$


Step 4: repeat the loop steps indicated in Figure 3 until the maximum number of iterations is reached or the termination cases are satisfied.

Step 5: if the number of iterations reaches its maximum, the loop process ends. The existing best known particle (chromosome) and fitness function value are selected as the optimal solution; otherwise, the above steps are repeated, starting from Step 2.

Step 6: the optimal solution is calculated and selected from all available chromosomes and serves as the final result for the CMPSRPMT.

4.2. Shapley Value Model and MPS. In the optimized CMPSRPMT, each PS arranges for delivery of refined oil from the nearest PD. Refined products' dispatching and distribution TS are implemented among PDs to reduce costs and increase profits. Alliance members agree to join the cooperation depending on the fairness of profit allocation. Participants are encouraged to join a coalition where the benefits are proportional to their contributions. Therefore, the leader or coordinator needs to implement an effective revenue delivery mechanism to ensure the group stability. The Shapley value model provides an efficient cost and profit allocation according to the participants' marginal contributions in cooperative game theory [43]. This theory is widely used in the study of cooperative behavior of participants, including their profit and cost savings allocation [44].

4.2.1. Shapley Value Model. The Shapley value is a solution concept that provides a unique solution to the cost allocation problem. The computation formula in the following expresses the cost to be allocated to participant $i$ based on the assumption that the grand coalition is formed by accepting new members one at a time. The Shapley value is the average marginal cost of participants that entered in a completely random order. The cost allocated to participant $i$ is equal to

$$
\psi_{i}=\sum_{S \subset N ; i c s} \frac{(|S|-1) !(|N|-|S|) !}{|N| !}[c(S)-c(S-\{i\})] .
$$

| $\mid$ represents the number of participants in the considered coalition. The summation is that of overall coalitions $S$ that contain participant $i$. The quantity, $c(S)-c(S-\{i\})$, is the amount by which the cost of coalition $S-\{i\}$ increases when participant $i$ decides to join. Such quantity is denoted by the marginal cost of participant $i$ with respect to that of coalition $S-\{i\}$.

The Shapley value model is based on four fairness properties, namely, efficiency, symmetry, dummy property, and additivity [22, 44]. The calculated cost and profit allocation strategy satisfies these four properties which show several expected features from a practical perspective. The reasonability and stability of allocation can be insured on this basis.

4.2.2. MPS Strategy. The strictly monotonic path (MPS) strategy [44] is mainly applied to estimate the group stability according to the cost and profit allocation. Large numbers of cooperation possibilities generally provide a wide range of cost and profit allocation manners. A sequence can be adopted only if the cost reduction percentage of each participant increases whenever a newcomer joins. If $\pi$ is a sequence of the coalition, $\pi(i)$ can denote the location of PD $i$ in sequence $\pi . \eta(i, \pi, u)$ indicates the cost reduction rate when PD $i$ joins the coalition as the $\mu^{\text {th }}$ member and can be computed as follows:

$$
\eta(i, \pi, u)=\frac{\psi_{i}\left(U_{\pi(u) \leq u, u \in S} \mu, v\right)}{C_{0}(i)}, \quad S \geq \pi(i) .
$$

In formula (24), $C_{0}(i)$ indicates that the participant $i$ decides not to join the cooperation. In the next section, the cost reduction percentages $\eta(i, \pi, u)$ are used to explain the SMP, a sequence wherein the cost reduction percentages for all committed participants monotonically increase with each new member. The above procedure is applied in the case study.

\section{Case Study}

5.1. Data Source. A practical study in Chongqing city in China is considered to evaluate the effectiveness of the proposed CMPSRPMT optimization. As the central city of China, Chongqing is an ideal research subject for this study. Figure 4 shows the locations of five PDs (denoted as PD1, PD2, .., PD5) and 65 PSs (denoted as PS1, PS2, .., PS65). The PSs are marked as follows: circles for those served by $\mathrm{PD} 1$; rectangles for those served by $\mathrm{PD} 2$; triangles for those served by PD3; cruciform for those served by PD4; and hexagons for those served by PD5. PDs are marked with solid five-pointed stars. Table 3 shows the initial service assignment in the petrol distribution network. Given the assumed constant transportation speed, the transportation time across facilities in the petrol replenishment network can be used to represent the transportation distance between them for the convenience of calculation. Table 4 shows the transportation time across facilities.

In this study, three kinds of refined products are considered, namely, nos. 92, 95, and 98. Table 5 shows the related data based on the demand for different kinds of refined products and the corresponding service time window of each PS.

5.2. Parameter Setting and Optimization Results. To ensure normal operations, PDs need to bear the fixed and variable costs related to their distribution tasks. Several parameter settings in the hybrid algorithm and model are determined according to the associated previous studies [1, 24, 41, 42] and real conditions as follows:

(1) Objective function parameters: three kinds of petrol distribution trucks are available. The set of petrol distribution trucks and their compartments are $\left\{a \mid a_{1}, a_{2}, a_{3}\right\}$ and $\left\{H_{a} \mid H_{a_{1}}=1 ; H_{a_{2}}=H_{a_{3}}=1,2\right\}$, respectively. Thus, $\left\{Q_{a}^{h} \mid Q_{a_{1}}^{1}=2000 ; Q_{a_{2}}^{1}=2000, Q_{a_{2}}^{2}=\right.$ $\left.4000 ; Q_{a_{3}}^{1}=3000, Q_{a_{3}}^{2}=4000\right\}, L_{o}=10000, f_{o}=20$, $\left\{f_{a} \mid f_{a_{1}}=10 ; f_{a_{2}}=15 ; f_{a_{3}}=16\right\}, \quad M_{o}=2500$, 


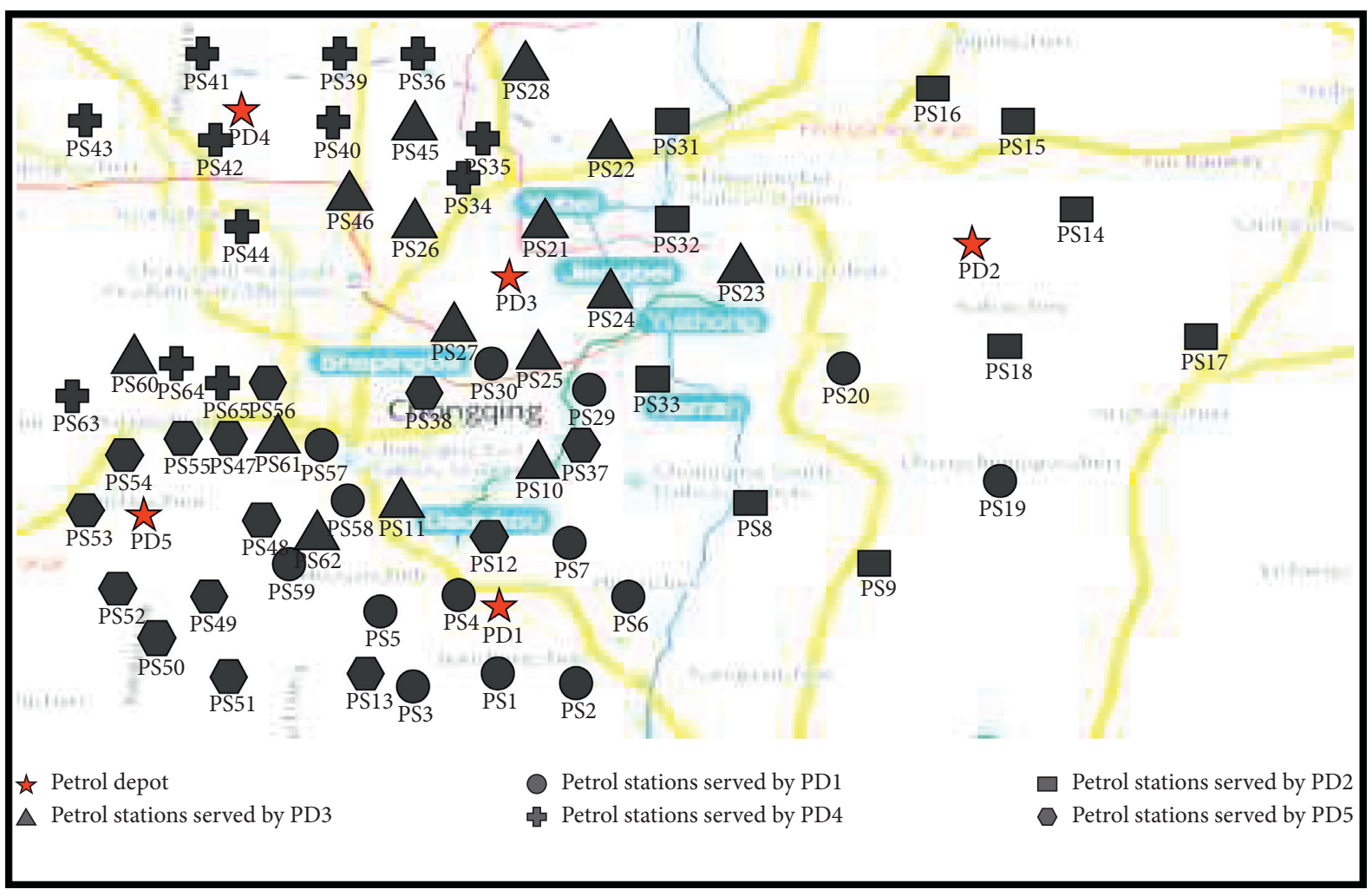

FIgURE 4: Petrol depots' and petrol stations' distribution diagram.

TABLE 3: Initial petrol stations' assignment.

\begin{tabular}{lc}
\hline Petrol depot & Petrol station \\
\hline PD1 1 & PS1 PS2 PS3 PS4 PS5 PS6 PS7 PS19 PS20 PS29 PS30 PS57 PS58 PS59 \\
PD2 & PS8 PS9 PS14 PS15 PS16 PS17 PS18 PS31 PS32 PS33 \\
PD3 & PS10 PS11 PS21 PS22 PS23 PS24 PS25 PS26 PS27 PS28 PS45 PS46 PS60 PS61 PS62 \\
PD4 & PS34 PS35 PS36 PS39 PS40 PS41 PS42 PS43 PS44 PS63 PS64 PS65 \\
PD5 & PS12 PS13 PS37 PS38 PS47 PS48 PS49 PS50 PS51 PS52 PS53 PS54 PS55 PS56 \\
\hline
\end{tabular}

$\left\{M_{a} \mid M_{a_{1}}=1000 ; M_{a_{2}}=2000 ; M_{a_{3}}=2200\right\}, \quad \omega_{1}=3$, $\omega_{2}=5, \gamma=0.002, \lambda=0.0045, G_{1}=438, G_{2}=375, G_{3}=$ $512, G_{4}=386$, and $G_{5}=504$.

(2) Algorithm parameters: according to Gao et al. [45], both PSO and GA are trained to get the best parameters in solving practical problems. Particles in PSO and the chromosomes in GA are trained by the dendritic neuron model (DNM), so as to get optimal parameter settings. $N=100$ is the popular size used to increase the diversity of initial chromosomes. $V_{g}=2$ expresses the maximum velocity for the refined products' distribution service. $p_{c}=0.8$ and $p_{m}=0.02$ indicate the crossover and mutation probabilities, respectively. $G=60$ indicates chromosomes as the initial particles in the population. $G G=30$ expresses the number of chromosomes for exchanges between GA and PSO. acc $=50$ denotes the number of iterations used for replacement between GA and PSO. $T_{o}^{\prime}=5$ represents the numbers of PDs for the refined products' distribution service. $M=100000$ is the penalty weight for each unqualified chromosome or particle. $S_{\max }=1000$ is the maximum number of iterations. $\omega_{\text {int }}=0.8$ is the initial inertia weight, and $\omega_{\text {end }}=0.3$ is the inertia weight of the maximum evolution generation. Moreover, $c_{1}=c_{2}=$ 2 is the coefficient used for PSO speed calculation.

In this study, a working period can be divided into several time periods. GA-PSO algorithm is used to assign PSs to corresponding PDs and compute the total cost in one time period. In particular, relevant government departments or core enterprises in the industry are encouraged to offer an initial subsidy, set at $7 \%$ of the cost, to those who wish to join the cooperation. Table 6 shows the optimization results, where $v(S)$ represents the cost difference before and after optimization. Table 6 shows the summary of the best PS allocation in the entire cooperation. 
TABle 4: Transportation times between facilities in the petrol replenishment network (hour).

\begin{tabular}{|c|c|c|c|c|c|}
\hline & PD1 & PD2 & PD3 & PD4 & PD5 \\
\hline PD1 & - & 2.5 & 1.8 & 2.3 & 1.6 \\
\hline PD2 & 2.5 & - & 2.1 & 2.7 & 2.8 \\
\hline PD3 & 1.8 & 2.1 & - & 1.7 & 2.0 \\
\hline $\mathrm{PD} 4$ & 2.3 & 2.7 & 1.7 & - & 2.2 \\
\hline PD5 & 1.6 & 2.8 & 2.0 & 2.2 & - \\
\hline PS1 & 0.7 & 1.8 & 1.2 & 1.8 & 1.3 \\
\hline PS2 & 0.8 & 1.7 & 1.3 & 1.9 & 1.4 \\
\hline PS3 & 0.8 & 1.9 & 1.2 & 1.8 & 1.2 \\
\hline PS4 & 0.4 & 1.6 & 1.0 & 1.6 & 1.2 \\
\hline PS5 & 0.9 & 2.0 & 1.1 & 1.7 & 1.0 \\
\hline PS6 & 1.2 & 1.6 & 1.3 & 1.9 & 1.5 \\
\hline PS7 & 1.0 & 1.7 & 1.1 & 1.7 & 1.4 \\
\hline PS8 & 1.3 & 1.6 & 1.5 & 1.8 & 1.7 \\
\hline PS9 & 1.4 & 1.6 & 1.7 & 2.0 & 1.8 \\
\hline PS10 & 0.6 & 1.8 & 0.8 & 1.5 & 1.2 \\
\hline PS11 & 0.6 & 1.8 & 0.9 & 1.3 & 1.0 \\
\hline PS12 & 0.3 & 1.7 & 1.1 & 1.5 & 1.2 \\
\hline PS13 & 0.4 & 2.1 & 1.2 & 1.8 & 1.0 \\
\hline PS14 & 2.2 & 0.7 & 1.6 & 1.8 & 2.4 \\
\hline PS15 & 2.3 & 0.8 & 1.6 & 1.7 & 2.5 \\
\hline PS16 & 2.2 & 0.9 & 1.5 & 1.6 & 2.3 \\
\hline PS17 & 2.0 & 0.8 & 1.8 & 2.0 & 2.6 \\
\hline PS18 & 1.7 & 0.5 & 1.5 & 1.6 & 2.4 \\
\hline PS19 & 1.8 & 0.8 & 1.5 & 1.5 & 2.0 \\
\hline PS20 & 2.0 & 0.6 & 1.2 & 1.3 & 2.2 \\
\hline PS21 & 1.2 & 1.1 & 0.3 & 0.6 & 1.3 \\
\hline PS22 & 1.5 & 1.2 & 0.6 & 0.8 & 1.6 \\
\hline PS23 & 1.1 & 0.8 & 0.6 & 0.9 & 1.3 \\
\hline PS24 & 1.0 & 1.1 & 0.3 & 0.7 & 1.1 \\
\hline PS25 & 0.8 & 1.3 & 0.2 & 1.0 & 1.2 \\
\hline PS26 & 1.1 & 1.6 & 0.4 & 0.6 & 1.2 \\
\hline PS27 & 0.9 & 1.5 & 0.4 & 0.7 & 1.1 \\
\hline PS28 & 1.8 & 1.1 & 0.7 & 0.8 & 1.7 \\
\hline PS29 & 1.2 & 1.1 & 0.6 & 0.9 & 1.0 \\
\hline PS30 & 1.3 & 1.5 & 0.5 & 1.2 & 1.6 \\
\hline PS31 & 2.2 & 1.6 & 0.7 & 1.5 & 2.3 \\
\hline PS32 & 1.6 & 1.3 & 0.6 & 1.6 & 2.0 \\
\hline PS33 & 1.5 & 1.4 & 0.6 & 1.8 & 1.9 \\
\hline PS34 & 1.3 & 1.3 & 0.4 & 0.7 & 1.1 \\
\hline PS35 & 1.4 & 1.2 & 0.5 & 0.8 & 1.2 \\
\hline PS36 & 1.5 & 1.2 & 0.6 & 0.8 & 1.3 \\
\hline PS37 & 0.6 & 1.4 & 0.5 & 1.2 & 1.3 \\
\hline PS38 & 0.7 & 1.4 & 0.4 & 1.0 & 1.2 \\
\hline PS39 & 1.5 & 1.6 & 0.7 & 0.5 & 1.3 \\
\hline PS40 & 1.4 & 1.6 & 0.6 & 0.2 & 1.2 \\
\hline PS41 & 1.5 & 1.7 & 0.9 & 0.5 & 1.1 \\
\hline PS42 & 1.4 & 1.6 & 0.8 & 0.1 & 1.0 \\
\hline PS43 & 1.4 & 1.7 & 0.9 & 0.6 & 1.0 \\
\hline PS44 & 1.2 & 1.6 & 0.7 & 0.4 & 0.7 \\
\hline PS45 & 1.4 & 1.5 & 0.6 & 0.5 & 1.1 \\
\hline PS46 & 1.3 & 1.6 & 0.6 & 0.3 & 1.0 \\
\hline PS47 & 1.0 & 1.8 & 1.0 & 1.1 & 0.5 \\
\hline PS48 & 0.9 & 1.7 & 1.1 & 1.2 & 0.4 \\
\hline PS49 & 0.9 & 1.8 & 1.2 & 1.3 & 0.3 \\
\hline PS50 & 1.0 & 1.9 & 1.3 & 1.4 & 0.4 \\
\hline PS51 & 0.9 & 1.8 & 1.4 & 1.5 & 0.5 \\
\hline PS52 & 1.0 & 2.0 & 1.3 & 1.3 & 0.2 \\
\hline PS53 & 1.1 & 2.1 & 1.1 & 1.1 & 0.3 \\
\hline PS54 & 1.1 & 1.9 & 1.0 & 1.0 & 0.4 \\
\hline
\end{tabular}

TABle 4: Continued.

\begin{tabular}{lccccc}
\hline & PD1 & PD2 & PD3 & PD4 & PD5 \\
\hline PS55 & 1.0 & 1.8 & 0.9 & 1.0 & 0.4 \\
PS56 & 0.9 & 1.6 & 0.8 & 0.8 & 0.6 \\
PS57 & 0.7 & 1.5 & 0.8 & 0.9 & 0.6 \\
PS58 & 0.7 & 1.5 & 0.9 & 1.1 & 0.6 \\
PS59 & 0.7 & 1.6 & 1.1 & 1.3 & 0.4 \\
PS60 & 1.1 & 1.9 & 1.2 & 0.8 & 0.6 \\
PS61 & 0.9 & 1.7 & 1.0 & 1.1 & 0.7 \\
PS62 & 0.7 & 1.5 & 1.2 & 1.5 & 0.5 \\
PS63 & 1.1 & 2.0 & 1.3 & 1.2 & 0.6 \\
PS64 & 0.9 & 1.8 & 1.2 & 1.0 & 0.5 \\
PS65 & 0.9 & 1.7 & 1.1 & 1.0 & 0.6 \\
\hline
\end{tabular}

Table 3 shows the initial PS allocation, while Table 7 shows the cooperative network. Clearly, the number of assigned PSs varies from a PD to another. Although several depots observe an increase, others are allocated fewer stations. For example, PD4's PSs decreased from 12 to 8, whereas PD5's PSs increased from 14 to 19. As a consequence, the total time travelled by each PD's trucks decreases, and savings increase. The sharing of distribution capacities and trucks allows PDs to reduce their number of distribution trucks.

For comparison purposes, we implement and test the proposed GA-PSO hybrid algorithm, PSO, HGA (hybrid genetic algorithm), and TS-ACO (tabu search and ant colony optimization hybrid algorithm) with same data. PSO simulates the social behavior of bird flocking and fish schooling [34]. HGA incorporates the elitism genetic operator and some improvement heuristic methods [46]. TSACO merges the ideas of ACO into a TS algorithm to achieve a balance between the diversification and the intensification [47]. Each algorithm is executed 20 times, and the best solution is selected as the optimal cost for convergence. The optimal total cost and the computational times can be used to measure the effectiveness of four algorithms shown in Table 8.

Compared with other three algorithms, the average optimization cost from our proposed algorithm is of better quality. In terms of computing time, in addition to PSO, the average computational time of our proposed algorithm also has significant advantages. Thus, we can conclude that GAPSO has the following merits: (1) exchanging best-fit chromosomes and worst-fit particles between the GA and the PSO algorithm enhances the GA-PSO's capability to obtain better solutions. For example, the GA-PSO algorithm has a higher probability to obtain the best solution. (2) The proposed algorithm combines GA and PSO algorithm's local and global search capabilities. As illustrated, the average cost from the proposed hybrid algorithm is lower than that of PSO, HGA, and TS-ACO algorithms by $4.8 \%, 3.4 \%$, and $2.4 \%$, respectively. (3) In the 20 runs, PSO is computed faster than the other three algorithms. Although GA-PSO requires slightly more computation time, the low average cost still makes this algorithm desirable in a practical setting where a slightly longer computation time can be tolerated (e.g., in 
TABle 5: The demand quantity and service time window of each petrol station in a time period (gallon).

\begin{tabular}{|c|c|c|c|c|}
\hline \multirow{2}{*}{ Petrol station } & \multicolumn{3}{|c|}{ Demand } & \multirow{2}{*}{ Time window } \\
\hline & No. 92 & No. 95 & No. 98 & \\
\hline PS1 & 3536 & 2929 & 1401 & $(600,800)$ \\
\hline PS2 & 2027 & 2877 & 56 & $(800,1000)$ \\
\hline PS3 & 2264 & 1191 & 1217 & $(800,1000)$ \\
\hline PS4 & 2097 & 1412 & 1284 & $(1000,1200)$ \\
\hline PS5 & 2514 & 1304 & 2000 & $(1000,1200)$ \\
\hline PS6 & 3288 & 1415 & 939 & $(1200,1400)$ \\
\hline PS7 & 3928 & 2856 & 972 & $(1400,1600)$ \\
\hline PS8 & 2617 & 1625 & 969 & $(1400,1600)$ \\
\hline PS9 & 2476 & 2612 & 1596 & $(1600,1800)$ \\
\hline PS10 & 2042 & 1570 & 1010 & $(1600,1800)$ \\
\hline PS11 & 2418 & 1641 & 699 & $(1800,2000)$ \\
\hline PS12 & 3593 & 2532 & 1045 & $(2000,2200)$ \\
\hline PS13 & 2174 & 1115 & 155 & $(2200,2400)$ \\
\hline PS14 & 3098 & 2484 & 1491 & $(1400,1600)$ \\
\hline PS15 & 3946 & 1430 & 260 & $(1000,1200)$ \\
\hline PS16 & 3047 & 1084 & 362 & $(1200,1400)$ \\
\hline PS17 & 2594 & 1453 & 1010 & $(800,1000)$ \\
\hline PS18 & 3177 & 2199 & 112 & $(1400,1600)$ \\
\hline PS19 & 3334 & 2740 & 471 & $(1000,1200)$ \\
\hline PS20 & 3013 & 1642 & 60 & $(2000,2200)$ \\
\hline PS21 & 2575 & 2634 & 956 & $(1000,1200)$ \\
\hline PS22 & 3075 & 2975 & 1237 & $(1200,1400)$ \\
\hline PS23 & 3976 & 1745 & 152 & $(800,1000)$ \\
\hline PS24 & 2737 & 2027 & 570 & $(1400,1600)$ \\
\hline PS25 & 2118 & 2043 & 704 & $(1200,1400)$ \\
\hline PS26 & 2052 & 1911 & 604 & $(1800,2000)$ \\
\hline PS27 & 3591 & 2252 & 1430 & $(1000,1200)$ \\
\hline PS28 & 2738 & 2312 & 308 & $(2000,2200)$ \\
\hline PS29 & 2132 & 2125 & 1437 & $(1400,1600)$ \\
\hline PS30 & 3556 & 1463 & 376 & $(800,1000)$ \\
\hline PS31 & 2691 & 1957 & 247 & $(600,800)$ \\
\hline PS32 & 2389 & 1552 & 1612 & $(1600,1800)$ \\
\hline PS33 & 3417 & 2172 & 215 & $(1000,1200)$ \\
\hline PS34 & 3558 & 1077 & 1718 & $(1200,1400)$ \\
\hline PS35 & 3177 & 1122 & 1845 & $(2200,2400)$ \\
\hline PS36 & 2783 & 1349 & 1325 & $(800,1000)$ \\
\hline PS37 & 3361 & 1676 & 1455 & $(2000,2200)$ \\
\hline PS38 & 3703 & 1757 & 1925 & $(1600,1800)$ \\
\hline PS39 & 2010 & 2857 & 409 & $(1000,1200)$ \\
\hline PS40 & 3869 & 1448 & 625 & $(2000,2200)$ \\
\hline PS41 & 3296 & 1147 & 1516 & $(1400,1600)$ \\
\hline PS42 & 2921 & 1954 & 659 & $(1800,2000)$ \\
\hline PS43 & 3392 & 2825 & 223 & $(1000,1200)$ \\
\hline PS44 & 3032 & 1318 & 1807 & $(1400,1600)$ \\
\hline PS45 & 2912 & 2733 & 192 & $(800,1000)$ \\
\hline PS46 & 3480 & 1299 & 455 & $(2000,2200)$ \\
\hline PS47 & 2545 & 1499 & 158 & $(1000,1200)$ \\
\hline PS48 & 3265 & 1655 & 540 & $(1400,1600)$ \\
\hline PS49 & 3285 & 1553 & 1954 & $(800,1000)$ \\
\hline PS50 & 3064 & 2706 & 1589 & $(2000,2200)$ \\
\hline PS51 & 3744 & 2850 & 87 & $(2200,2400)$ \\
\hline PS52 & 3237 & 2556 & 157 & $(1200,1400)$ \\
\hline PS53 & 2367 & 2895 & 60 & $(1600,1800)$ \\
\hline PS54 & 3547 & 2843 & 263 & $(1400,1600)$ \\
\hline PS55 & 3851 & 1504 & 772 & $(1000,1200)$ \\
\hline PS56 & 3164 & 1089 & 593 & $(1800,2000)$ \\
\hline PS57 & 2770 & 2146 & 1751 & $(2000,2200)$ \\
\hline PS58 & 3495 & 2652 & 271 & $(1600,1800)$ \\
\hline PS59 & 3916 & 1207 & 116 & $(1400,1600)$ \\
\hline PS60 & 3496 & 1489 & 138 & $(1800,2000)$ \\
\hline PS61 & 3984 & 1329 & 204 & $(2000,2200)$ \\
\hline PS62 & 2815 & 2650 & 292 & $(1200,1400)$ \\
\hline PS63 & 3032 & 1798 & 717 & $(1000,1200)$ \\
\hline PS64 & 2994 & 1017 & 1565 & $(600,800)$ \\
\hline PS65 & 2811 & 2148 & 885 & $(800,1000)$ \\
\hline
\end{tabular}


TABLE 6: Comparison between the initial and optimized network over one time period (unit: USD).

\begin{tabular}{|c|c|c|c|}
\hline$S$ & Initial cost & Optimized cost & $v(S)$ \\
\hline$\{\mathrm{PD} 1\}$ & 1382.87 & 1086.07 & 96.80 \\
\hline$\{\mathrm{PD} 2\}$ & 1086.90 & 1010.82 & 76.08 \\
\hline$\{\mathrm{PD} 3\}$ & 1231.99 & 1145.75 & 86.24 \\
\hline$\{\mathrm{PD} 4\}$ & 970.79 & 902.83 & 67.96 \\
\hline$\{\mathrm{PD} 5\}$ & 1157.70 & 1076.66 & 81.04 \\
\hline$\{\mathrm{PD} 1 \mathrm{PD} 2\}$ & 2469.77 & 2074.34 & 395.43 \\
\hline$\{\mathrm{PD} 1 \mathrm{PD} 3\}$ & 2614.86 & 2143.21 & 471.65 \\
\hline$\{$ PD1 PD4 $\}$ & 2353.66 & 2053.49 & 300.17 \\
\hline$\{\mathrm{PD} 1 \mathrm{PD} 5\}$ & 2540.57 & 2102.84 & 437.73 \\
\hline$\{\mathrm{PD} 2 \mathrm{PD} 3\}$ & 2318.89 & 1875.41 & 433.48 \\
\hline$\{\mathrm{PD} 2 \mathrm{PD} 4\}$ & 2057.69 & 1808.63 & 249.06 \\
\hline$\{\mathrm{PD} 2 \mathrm{PD} 5\}$ & 2244.60 & 1949.18 & 295.42 \\
\hline$\{$ PD3 PD4 $\}$ & 2202.78 & 1843.52 & 359.26 \\
\hline$\{$ PD3 PD5 $\}$ & 2389.69 & 1892.67 & 497.02 \\
\hline$\{\mathrm{PD} 4 \mathrm{PD} 5\}$ & 2128.49 & 1780.36 & 348.13 \\
\hline$\{P D 1 P D 2 P D 3\}$ & 3701.76 & 2807.26 & 894.50 \\
\hline$\{\mathrm{PD} 1 \mathrm{PD} 2 \mathrm{PD} 4\}$ & 3440.56 & 2886.14 & 554.42 \\
\hline$\{\mathrm{PD} 1 \mathrm{PD} 2 \mathrm{PD} 5\}$ & 3627.47 & 2895.92 & 731.55 \\
\hline$\{\mathrm{PD} 1 \mathrm{PD} 3 \mathrm{PD} 4\}$ & 3585.65 & 2909.23 & 676.42 \\
\hline$\{P D 1$ PD3 PD5 $\}$ & 3772.56 & 2904.58 & 867.98 \\
\hline$\{\mathrm{PD} 1 \mathrm{PD} 4 \mathrm{PD} 5\}$ & 3511.36 & 2804.67 & 706.69 \\
\hline$\{\mathrm{PD} 2 \mathrm{PD} 3 \mathrm{PD} 4\}$ & 3289.68 & 2651.37 & 638.31 \\
\hline$\{P D 2$ PD3 PD5 $\}$ & 3476.59 & 2697.79 & 778.80 \\
\hline$\{\mathrm{PD} 2 \mathrm{PD} 4 \mathrm{PD} 5\}$ & 3215.39 & 2700.79 & 514.60 \\
\hline$\{$ PD3 PD4 PD5 $\}$ & 3360.48 & 2607.36 & 753.12 \\
\hline$\{\mathrm{PD} 1 \mathrm{PD} 2 \mathrm{PD} 3 \mathrm{PD} 4\}$ & 4672.55 & 3665.71 & 1006.84 \\
\hline$\{P D 1$ PD2 PD3 PD5 $\}$ & 4859.46 & 3651.67 & 1207.79 \\
\hline$\{\mathrm{PD} 1 \mathrm{PD} 2 \mathrm{PD} 4 \mathrm{PD} 5\}$ & 4598.26 & 3657.80 & 940.46 \\
\hline$\{P D 1$ PD3 PD4 PD5 $\}$ & 4743.35 & 3600.45 & 1142.90 \\
\hline$\{\mathrm{PD} 2 \mathrm{PD} 3 \mathrm{PD} 4 \mathrm{PD} 5\}$ & 4447.38 & 3408.81 & 1038.57 \\
\hline$\{\mathrm{PD} 1 \mathrm{PD} 2 \mathrm{PD} 3 \mathrm{PD} 4 \mathrm{PD} 5\}$ & 5830.25 & 4354.57 & 1475.68 \\
\hline
\end{tabular}

TABle 7: Petrol stations' assignment in the grand coalition.

\begin{tabular}{lc}
\hline Petrol depot & Petrol station \\
\hline PD1 & PS1 PS2 PS3 PS4 PS5 PS6 PS7 PS8 PS9 PS10 PS11 PS12 PS13 \\
PD2 & PS14 PS15 PS16 PS17 PS18 PS19 PS20 \\
PD3 & PS21 PS22 PS23 PS24 PS25 PS26 PS27 PS28 PS29 PS30 PS31 PS32 \\
PD4 & PS33 PS34 PS35 PS36 PS37 PS38 \\
PD5 & PS39 PS40 PS41 PS42 PS43 PS44 PS45 PS46 \\
& PS47 PS48 PS49 PS50 PS51 PS52 PS53 PS54 PS55 PS56 PS57 PS58 PS59 PS60 \\
\hline
\end{tabular}

operation management). Therefore, we conclude that the proposed GA-PSO hybrid algorithm is superior to the three existing algorithms when optimizing multidepot refined products' distribution networks.

Comparison between the cost changes and the use of distribution trucks before and after the cooperation enables the intuitive analysis of the benefits of the collaborative PS replenishment network. Figures 5 and 6 show the cost reduction and the variations before and after the formation of the cooperation. Compared with the previous numbers, operating costs significantly decreased after the formation of cooperation among PDs. Cost savings also increased with the high number of PDs joining the collaborative petrol distribution network. Whether for a single or multiple PDs, the number of required petrol distribution trucks decreased due to the cooperation and resource sharing among PDs. Table 9 illustrates the optimization of distribution trucks.

In the CMPSRPMT, TS is an important mechanism. A $\mathrm{PD}$ joining the cooperation can coordinate the sharing of petrol distribution trucks. Before cooperation, the PSs' demands and the required service TWS for each PD must be considered. Then, the largest numbers of delivery trucks are needed to certify customer satisfaction. After cooperation, a chronological and overall time window plan can be made for all PDs. Trucks can be shared and reasonably arranged, 
TABLE 8: Comparison of algorithms' performance.

\begin{tabular}{|c|c|c|c|c|c|c|c|c|}
\hline \multirow{2}{*}{ Sequence } & \multicolumn{4}{|c|}{ Total cost(USD) } & \multicolumn{4}{|c|}{ Time $*(\mathrm{~s})$} \\
\hline & GA-PSO & PSO & HGA & TS-ACO & GA-PSO & PSO & HGA & TS-ACO \\
\hline 1 & 4355 & 4604 & 4463 & 4444 & 184 & 100 & 269 & 186 \\
\hline 2 & 4338 & 4523 & 4544 & 4452 & 167 & 122 & 219 & 216 \\
\hline 3 & 4344 & 4562 & 4462 & 4486 & 214 & 103 & 212 & 194 \\
\hline 4 & 4310 & 4562 & 4540 & 4463 & 177 & 92 & 269 & 180 \\
\hline 5 & 4388 & 4546 & 4541 & 4419 & 218 & 91 & 275 & 314 \\
\hline 6 & 4307 & 4550 & 4510 & 4493 & 163 & 114 & 253 & 214 \\
\hline 7 & 4359 & 4595 & 4502 & 4467 & 243 & 105 & 197 & 258 \\
\hline 8 & 4374 & 4608 & 4491 & 4436 & 162 & 125 & 172 & 216 \\
\hline 9 & 4395 & 4565 & 4556 & 4449 & 167 & 95 & 250 & 199 \\
\hline 10 & 4313 & 4598 & 4552 & 4422 & 215 & 102 & 183 & 253 \\
\hline 11 & 4389 & 4601 & 4488 & 4484 & 155 & 154 & 249 & 308 \\
\hline 12 & 4316 & 4540 & 4478 & 4478 & 230 & 107 & 228 & 253 \\
\hline 13 & 4380 & 4524 & 4484 & 4417 & 181 & 148 & 240 & 279 \\
\hline 14 & 4311 & 4530 & 4469 & 4465 & 198 & 131 & 225 & 238 \\
\hline 15 & 4354 & 4597 & 4483 & 4494 & 238 & 123 & 259 & 281 \\
\hline 16 & 4347 & 4549 & 4515 & 4501 & 163 & 105 & 197 & 189 \\
\hline 17 & 4374 & 4552 & 4495 & 4437 & 237 & 144 & 255 & 311 \\
\hline 18 & 4389 & 4563 & 4474 & 4452 & 197 & 103 & 242 & 198 \\
\hline 19 & 4309 & 4549 & 4491 & 4433 & 151 & 128 & 179 & 261 \\
\hline 20 & 4377 & 4518 & 4485 & 4453 & 167 & 108 & 230 & 184 \\
\hline Average & 4351.45 & 4561.80 & 4501.15 & 4457.25 & 191.35 & 115.00 & 230.15 & 236.60 \\
\hline
\end{tabular}

* Time refers to the average computational time (seconds) for one run.

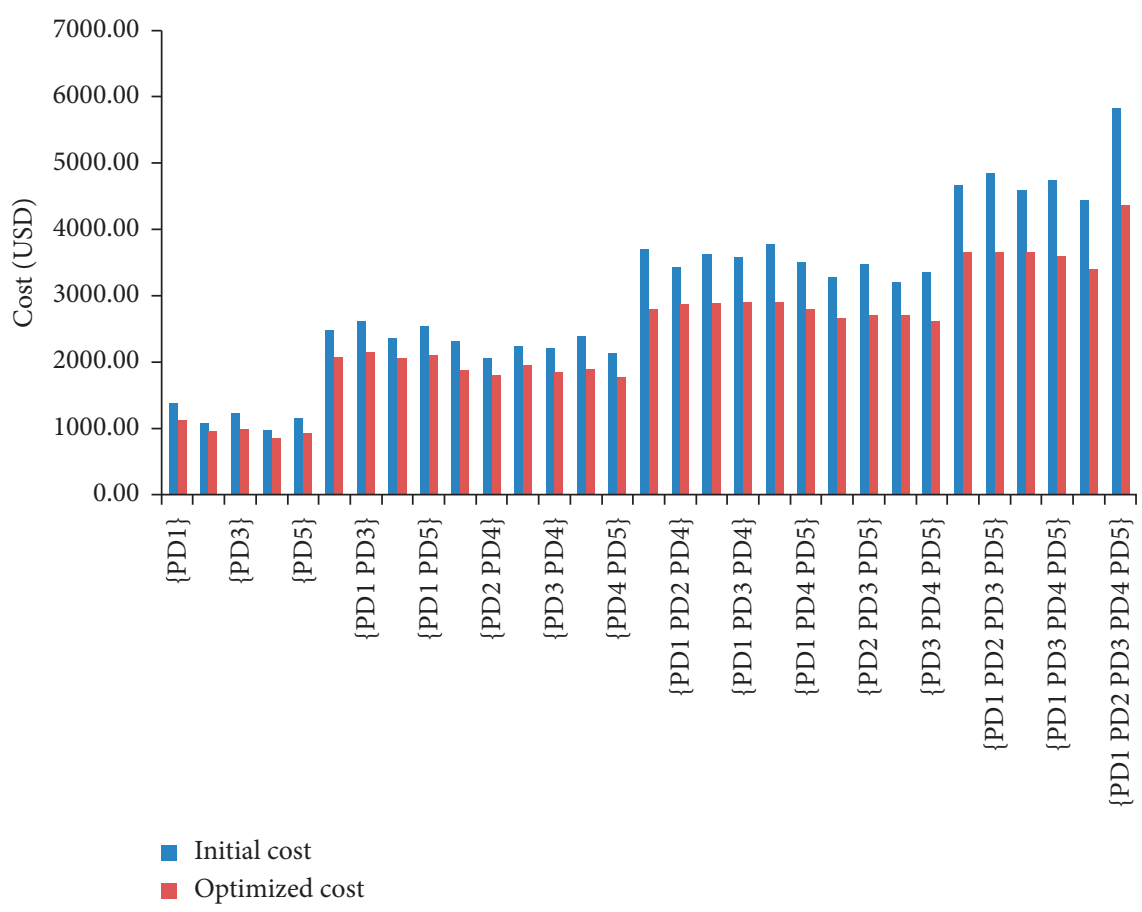

Figure 5: Comparison between initial and optimized networks' cost solutions.

which greatly decreases the required number of total petrol distribution trucks in the network. For example, Table 8 shows that truck usage decreases from $\left(15 \mathrm{a}_{1}, 9 \mathrm{a}_{2}, 10_{3}\right)$ to $\left(4 \mathrm{a}_{1}, 2 \mathrm{a}_{2}, 2 \mathrm{a}_{3}\right)$ for $\{$ PD1 PD3 PD5 $\}$, which significantly reduced $11 a_{1}, 7 a_{2}$, and $8 a_{3}$.
5.3. Model Comparison. Based on the above parameter settings, the cost and the number of distribution trucks of integrated MILP are calculated. Then, we compared them with the model calculation results adopted in this study. The comparison is shown in Table 10. According to the table, 


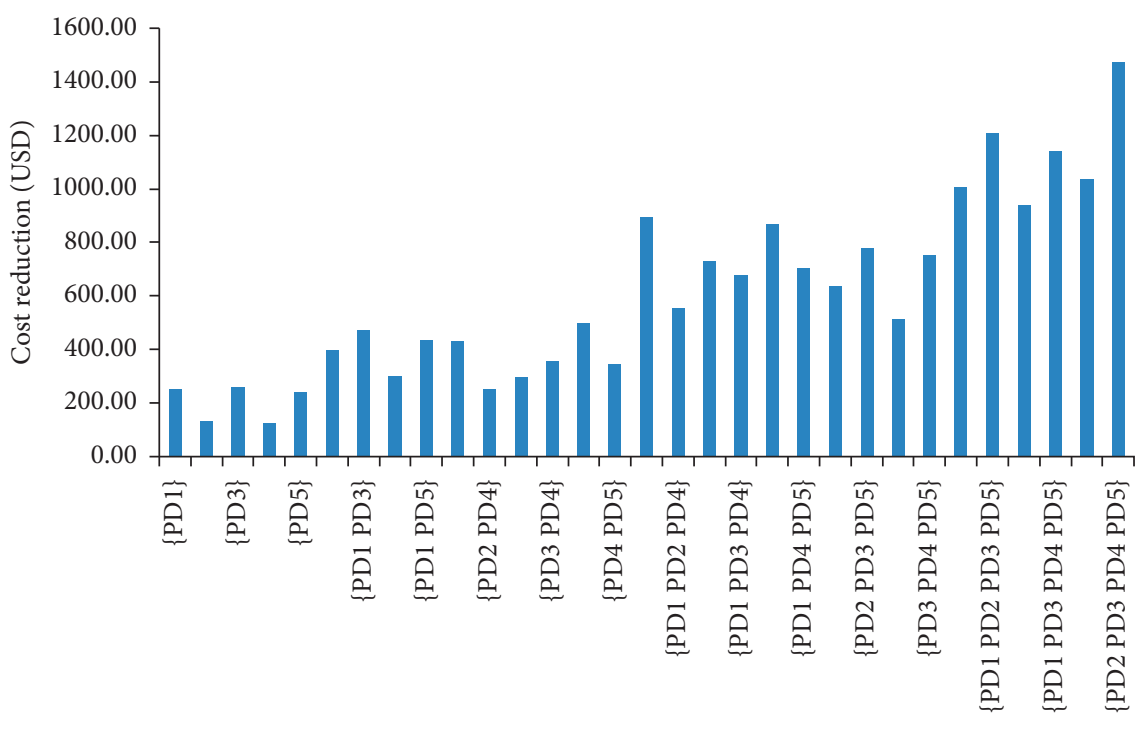

$v(S)$

FIgURE 6: Cost reduction variations of different coalitions.

TABLE 9: Comparison of the truck usage between initial and optimized networks.

\begin{tabular}{|c|c|c|c|}
\hline$S$ & Initial truck usage & Truck usage after optimization & The saving of truck usage \\
\hline$\{\mathrm{PD} 1\}$ & $4 \mathrm{a} 1,3 \mathrm{a} 2,4 \mathrm{a} 3$ & - & - \\
\hline$\{\mathrm{PD} 2\}$ & $3 \mathrm{a} 1,3 \mathrm{a} 2,2 \mathrm{a} 3$ & - & - \\
\hline$\{\mathrm{PD} 3\}$ & $5 \mathrm{a} 1,3 \mathrm{a} 2,4 \mathrm{a} 3$ & - & - \\
\hline$\{\mathrm{PD} 4\}$ & $4 \mathrm{a} 1,4 \mathrm{a} 2,2 \mathrm{a} 3$ & - & - \\
\hline$\{\mathrm{PD} 5\}$ & $6 \mathrm{a} 1,3 \mathrm{a} 2,2 \mathrm{a} 3$ & - & - \\
\hline$\{\mathrm{PD} 1 \mathrm{PD} 2\}$ & $7 \mathrm{a} 1,6 \mathrm{a} 2,6 \mathrm{a} 3$ & $3 \mathrm{a} 1,2 \mathrm{a} 2,3 \mathrm{a} 3$ & $4 \mathrm{a} 1,4 \mathrm{a} 2,3 \mathrm{a} 3$ \\
\hline$\{\mathrm{PD} 1 \mathrm{PD} 3\}$ & $9 \mathrm{a} 1,6 \mathrm{a} 2,8 \mathrm{a} 3$ & $3 \mathrm{a} 1,2 \mathrm{a} 2,2 \mathrm{a} 3$ & $6 \mathrm{a} 1,4 \mathrm{a} 2,6 \mathrm{a} 3$ \\
\hline$\{\mathrm{PD} 1 \mathrm{PD} 4\}$ & $8 \mathrm{a} 1,7 \mathrm{a} 2,6 \mathrm{a} 3$ & $3 \mathrm{a} 1,2 \mathrm{a} 2,2 \mathrm{a} 3$ & $5 \mathrm{a} 1,5 \mathrm{a} 2,4 \mathrm{a} 3$ \\
\hline$\{\mathrm{PD} 1 \mathrm{PD} 5\}$ & $10 \mathrm{a} 1,6 \mathrm{a} 2,6 \mathrm{a} 3$ & $3 \mathrm{a} 1,2 \mathrm{a} 2,2 \mathrm{a} 3$ & $7 \mathrm{a} 1,4 \mathrm{a} 2,4 \mathrm{a} 3$ \\
\hline$\{\mathrm{PD} 2 \mathrm{PD} 3\}$ & $8 \mathrm{a} 1,6 \mathrm{a} 2,6 \mathrm{a} 3$ & $2 \mathrm{a} 1,2 \mathrm{a} 2,2 \mathrm{a} 3$ & $6 \mathrm{a} 1,4 \mathrm{a} 2,4 \mathrm{a} 3$ \\
\hline$\{\mathrm{PD} 2 \mathrm{PD} 4\}$ & $7 \mathrm{a} 1,7 \mathrm{a} 2,4 \mathrm{a} 3$ & $3 \mathrm{a} 1,2 \mathrm{a} 2,2 \mathrm{a} 3$ & $4 \mathrm{a} 1,5 \mathrm{a} 2,2 \mathrm{a} 3$ \\
\hline$\{\mathrm{PD} 2 \mathrm{PD} 5\}$ & $9 \mathrm{a} 1,6 \mathrm{a} 2,4 \mathrm{a} 3$ & $3 \mathrm{a} 1,2 \mathrm{a} 2,2 \mathrm{a} 3$ & $6 \mathrm{a} 1,4 \mathrm{a} 2,2 \mathrm{a} 3$ \\
\hline$\{$ PD3 PD4 $\}$ & $9 \mathrm{a} 1,7 \mathrm{a} 2,6 \mathrm{a} 3$ & $3 \mathrm{a} 1,2 \mathrm{a} 2,2 \mathrm{a} 3$ & $6 \mathrm{a} 1,5 \mathrm{a} 2,4 \mathrm{a} 3$ \\
\hline$\{$ PD3 PD5 $\}$ & $11 \mathrm{a} 1,6 \mathrm{a} 2,6 \mathrm{a} 3$ & $3 \mathrm{a} 1,2 \mathrm{a} 2,2 \mathrm{a} 3$ & $8 \mathrm{a} 1,4 \mathrm{a} 2,4 \mathrm{a} 3$ \\
\hline$\{\mathrm{PD} 4 \mathrm{PD} 5\}$ & $10 \mathrm{a} 1,7 \mathrm{a} 2,4 \mathrm{a} 3$ & $3 \mathrm{a} 1,2 \mathrm{a} 2,2 \mathrm{a} 3$ & $7 \mathrm{a} 1,5 \mathrm{a} 2,2 \mathrm{a} 3$ \\
\hline$\{\mathrm{PD} 1 \mathrm{PD} 2 \mathrm{PD} 3\}$ & $12 \mathrm{a} 1,9 \mathrm{a} 2,10 \mathrm{a} 3$ & $4 \mathrm{a} 1,2 \mathrm{a} 2,2 \mathrm{a} 3$ & $8 \mathrm{a} 1,7 \mathrm{a} 2,8 \mathrm{a} 1$ \\
\hline$\{P D 1 P D 2 P D 4\}$ & $11 \mathrm{a} 1,10 \mathrm{a} 2,8 \mathrm{a} 3$ & $4 \mathrm{a} 1,2 \mathrm{a} 2,2 \mathrm{a} 3$ & $7 \mathrm{a} 1,8 \mathrm{a} 2,6 \mathrm{a} 3$ \\
\hline$\{\mathrm{PD} 1 \mathrm{PD} 2 \mathrm{PD} 5\}$ & $13 \mathrm{a} 1,9 \mathrm{a} 2,8 \mathrm{a} 3$ & $4 \mathrm{a} 1,2 \mathrm{a} 2,3 \mathrm{a} 3$ & $9 \mathrm{a} 1,7 \mathrm{a} 2,5 \mathrm{a} 3$ \\
\hline$\{P D 1$ PD3 PD4 $\}$ & $13 \mathrm{a} 1,10 \mathrm{a} 2,10 \mathrm{a} 3$ & $4 \mathrm{a} 1,2 \mathrm{a} 2,2 \mathrm{a} 3$ & $9 \mathrm{a} 1,8 \mathrm{a} 2,8 \mathrm{a} 3$ \\
\hline$\{\mathrm{PD} 1 \mathrm{PD} 3 \mathrm{PD} 5\}$ & $15 \mathrm{a} 1,9 \mathrm{a} 2,10 \mathrm{a} 3$ & $4 \mathrm{a} 1,2 \mathrm{a} 2,2 \mathrm{a} 3$ & $11 \mathrm{a} 1,7 \mathrm{a} 2,8 \mathrm{a} 3$ \\
\hline$\{\mathrm{PD} 1 \mathrm{PD} 4 \mathrm{PD} 5\}$ & $14 \mathrm{a} 1,10 \mathrm{a} 2,8 \mathrm{a} 3$ & $4 \mathrm{a} 1,2 \mathrm{a} 2,2 \mathrm{a} 3$ & $10 \mathrm{a} 1,8 \mathrm{a} 2,6 \mathrm{a} 3$ \\
\hline$\{\mathrm{PD} 2 \mathrm{PD} 3 \mathrm{PD} 4\}$ & $12 \mathrm{a} 1,10 \mathrm{a} 2,8 \mathrm{a} 3$ & $4 \mathrm{a} 1,2 \mathrm{a} 2,2 \mathrm{a} 3$ & $8 \mathrm{a} 1,8 \mathrm{a} 2,6 \mathrm{a} 3$ \\
\hline$\{\mathrm{PD} 2 \mathrm{PD} 3 \mathrm{PD} 5\}$ & $14 \mathrm{a} 1,9 \mathrm{a} 2,8 \mathrm{a} 3$ & $3 \mathrm{a} 1,2 \mathrm{a} 2,2 \mathrm{a} 3$ & $11 \mathrm{a} 1,7 \mathrm{a} 2,6 \mathrm{a} 3$ \\
\hline$\{\mathrm{PD} 2 \mathrm{PD} 4 \mathrm{PD} 5\}$ & $13 \mathrm{a} 1,10 \mathrm{a} 2,6 \mathrm{a} 3$ & $4 \mathrm{a} 1,2 \mathrm{a} 2,1 \mathrm{a} 3$ & $9 \mathrm{a} 1,8 \mathrm{a} 2,5 \mathrm{a} 3$ \\
\hline$\{\mathrm{PD} 3 \mathrm{PD} 4 \mathrm{PD} 5\}$ & $15 \mathrm{a} 1,10 \mathrm{a} 2,8 \mathrm{a} 3$ & $3 \mathrm{a} 1,2 \mathrm{a} 2,2 \mathrm{a} 3$ & $12 \mathrm{a} 1,8 \mathrm{a} 2,6 \mathrm{a} 3$ \\
\hline$\{\mathrm{PD} 1 \mathrm{PD} 2 \mathrm{PD} 3 \mathrm{PD} 4\}$ & $16 \mathrm{a} 1,13 \mathrm{a} 2,12 \mathrm{a} 3$ & $5 \mathrm{a} 1,3 \mathrm{a} 2,2 \mathrm{a} 3$ & $11 \mathrm{a} 1,10 \mathrm{a} 2,10 \mathrm{a} 3$ \\
\hline$\{P D 1$ PD2 PD3 PD5 $\}$ & $18 \mathrm{a} 1,12 \mathrm{a} 2,12 \mathrm{a} 3$ & $5 \mathrm{a} 1,2 \mathrm{a} 2,3 \mathrm{a} 3$ & $13 \mathrm{a} 1,10 \mathrm{a} 2,9 \mathrm{a} 3$ \\
\hline$\{\mathrm{PD} 1 \mathrm{PD} 2 \mathrm{PD} 4 \mathrm{PD} 5\}$ & $17 \mathrm{a} 1,13 \mathrm{a} 2,10 \mathrm{a} 3$ & $5 \mathrm{a} 1,3 \mathrm{a} 2,2 \mathrm{a} 3$ & $12 \mathrm{a} 1,10 \mathrm{a} 2,8 \mathrm{a} 3$ \\
\hline$\{P D 1$ PD3 PD4 PD5 $\}$ & $19 \mathrm{a} 1,13 \mathrm{a} 2,12 \mathrm{a} 3$ & $5 \mathrm{a} 1,3 \mathrm{a} 2,3 \mathrm{a} 3$ & $14 \mathrm{a} 1,10 \mathrm{a} 2,9 \mathrm{a} 3$ \\
\hline$\{\mathrm{PD} 2 \mathrm{PD} 3 \mathrm{PD} 4 \mathrm{PD} 5\}$ & $18 \mathrm{a} 1,13 \mathrm{a} 2,10 \mathrm{a} 3$ & $4 \mathrm{a} 1,2 \mathrm{a} 2,2 \mathrm{a} 3$ & $14 \mathrm{a} 1,11 \mathrm{a} 2,8 \mathrm{a} 3$ \\
\hline$\{\mathrm{PD} 1 \mathrm{PD} 2 \mathrm{PD} 3 \mathrm{PD} 4 \mathrm{PD} 5\}$ & $22 \mathrm{a} 1,16 \mathrm{a} 2,14 \mathrm{a} 3$ & $6 \mathrm{a} 1,3 \mathrm{a} 2,3 \mathrm{a} 3$ & $16 \mathrm{a} 1,13 \mathrm{a} 2,11 \mathrm{a} 3$ \\
\hline
\end{tabular}

Note. a1, a2, and a3 represent three kinds of petrol distribution trucks with different loads and different compartments. 
TABle 10: Model comparison.

\begin{tabular}{lccccc}
\hline & Transportation cost $(\$)$ & Penalty cost $(\$)$ & Cooperation cost $(\$)$ & Total cost $(\$)$ & The number of distribution trucks \\
\hline Integrated MILP & 4560.62 & 315.62 & - & 4876.24 & $18 \mathrm{a} 1,16 \mathrm{a} 2,10 \mathrm{a} 3$ \\
This study & 3900.19 & 204.38 & 250 & 4354.57 & $16 \mathrm{a} 1,13 \mathrm{a} 2,11 \mathrm{a} 3$ \\
\hline
\end{tabular}

significant decline in the total cost and the number of distribution trucks can be observed by the model of this study. Because the model adopted in this study not only includes the MDVRP but also readjusts the customer groups served by each PD through the cooperation among PDs with the feedback mechanism, better results are obtained.

5.4. Stability of the Coalition. Many game theory-based approaches to allocating profits are available. In this study, minimum cost-remaining savings (MCRS), GQP, the improved Shapley value model, and the equal profit method (EPM) are adopted to conduct a comparative analysis that tests the stability of alliance [44]. We explore the grand coalition scenario where five PDs form a single coalition and evaluate the profit allocated to each of the five PDs (called "profit allocation scheme" throughout the paper) under the four game theory models. The core of the most stable profit allocation scheme can be calculated using formula 25. Based on our network where five petrol depots constitute an alliance, the core area forms a closed polygon. Each surface of the core area is compressed and narrowed into a single point, which is the core center. $\kappa$ represents a member, and $\varepsilon$ is a variable for controlling its range. The center can be expressed as follows:

$$
\frac{v(N)-v(N-\{\kappa\})}{v(N)} \times \varepsilon+\sum_{c \in N}^{c \neq \kappa} y_{c}=v(N-\{\kappa\})
$$

According to the snowball theory, the proximity of a profit distribution scheme to the core center reflects the stability of the alliance with the given profit distribution scheme [48]. In particular, a profit allocation scheme that is near the core center indicates a robust coalition strategy. Following formula (25), the core center is calculated as (333, $281,368,206,298)$. The profit allocation schemes under the four game theory models and their distances to the core center are summarized in Table 11.

Table 11 shows the distance between profit allocation schemes and the core center, with the most stable scheme at the center and the other schemes at the periphery. The profit allocation scheme calculated by the Shapley model is nearest to the core center and thus is superior to the other three models. The comparison result confirms that the Shapley model outperforms the other methods in terms of stability. The profit allocation schemes under the MCRS and the EPM are unstable given their long distance from the core center. Therefore, among the four profit allocation schemes, the profit allocation scheme obtained from the Shapley model will result in the highest probability of participants agreeing to cooperate.

5.5. Shapley Value Model Application and Coalition Sequence Selection. Upon the CMPSRPMT optimization, the benefits and cost savings should be reasonably allocated among each depot to ensure the long-term group stability. Then, the Shapley value model and the SMP method introduced above are applied to determine the benefit allocation and order analysis of membership.

5.5.1. Shapley Value Model Application. According to formula (23), Table 12 shows the cost saving allocation of each PD analyzed under different collaborations.

Table 12 shows the cost savings of each alliance and the profit allocation of each PD as computed using the Shapley value model. In the final grand alliance, PD1, PD2, PD3, PD4, and PD5 gain cost savings amounting to $\$ 327.10$, $\$ 270.79$, \$376.82, \$199.55, and \$301.42, respectively. However, forming a grand alliance is difficult, requiring the communication and coordination of each participant and the fair and reasonable allocation of cost savings and benefits.

5.5.2. Sequential Alliance Selection. The analysis of cooperation sequences is extremely important for the benefit allocation strategy and the participants' willingness to join. In other words, the order in which the participants join the cooperation affects the allocation of benefits and the satisfaction of SMP principles. Figure 7 shows the proportions of cost reduction during the formation of the CMPSRPMT computed according to formula (24).

Formula (23) is used to calculate the cost saving percentages and changes of different membership orders. The optimal sequence with PD1, PD2, PD3, PD4, and PD5 is determined. Table 13 shows the first member.

In the five sequences, the cost reduction percentage for each PD reflects the results of taking different PDs as first participants. The optimal cooperation sequence of coalition is $\pi_{3}=\{\mathrm{PD} 3, \mathrm{PD} 5, \mathrm{PD} 4, \mathrm{PD} 1, \mathrm{PD} 2\}$, determined from the five sequences using the method analyzed in Section 4.2.2. Table 14 shows the specific cost reduction percentages, and Figure 8 shows their changes. 
TABle 11: Distance between schemes and the core center location.

\begin{tabular}{lccc}
\hline Profit allocation model & Profit allocation schemes & Core center & Distance \\
\hline MCRS & $(338,297,348,226,289)$ & $(333,281,368,206,298)$ & 70 \\
GQP & $(336,290,351,214,273)$ & - & 62 \\
Shapley & $(327,271,377,200,301)$ & - & 34 \\
EPM & $(347,301,382,233,285)$ & - & 88 \\
\hline
\end{tabular}

TABLE 12: Cost allocation in the CMPSRPMT optimization with one alliance (unit: USD).

\begin{tabular}{|c|c|c|}
\hline$S$ & $v(S)$ & $\psi(i, v)$ \\
\hline$\{\mathrm{PD} 1\}$ & 96.80 & $(96.80,0,0,0,0)$ \\
\hline$\{\mathrm{PD} 2\}$ & 76.08 & $(0,76.08,0,0,0)$ \\
\hline$\{\mathrm{PD} 3\}$ & 86.24 & $(0,0,86.24,0,0)$ \\
\hline$\{\mathrm{PD} 4\}$ & 67.96 & $(0,0,0,67.96,0)$ \\
\hline$\{\mathrm{PD} 5\}$ & 81.04 & $(0,0,0,0,81.04)$ \\
\hline$\{\mathrm{PD} 1 \mathrm{PD} 2\}$ & 395.43 & $(208.08,187.35,0,0,0)$ \\
\hline$\{\mathrm{PD} 1 \mathrm{PD} 3\}$ & 471.65 & $(241.11,0,230.54,0,0)$ \\
\hline$\{\mathrm{PD} 1 \mathrm{PD} 4\}$ & 300.17 & $(164.51,0,0,135.66,0)$ \\
\hline$\{\mathrm{PD} 1 \mathrm{PD} 5\}$ & 437.73 & $(226.75,0,0,0,210.98)$ \\
\hline$\{\mathrm{PD} 2 \mathrm{PD} 3\}$ & 433.48 & $(0,211.66,221.82,0,0)$ \\
\hline$\{\mathrm{PD} 2 \mathrm{PD} 4\}$ & 249.06 & $(0,128.59,0,120.50,0)$ \\
\hline$\{\mathrm{PD} 2 \mathrm{PD} 5\}$ & 295.42 & $(0,145.23,0,0,150.19)$ \\
\hline$\{$ PD3 PD4 $\}$ & 359.26 & $(0,0,188.77,170.49,0)$ \\
\hline$\{$ PD3 PD5 $\}$ & 497.02 & $(0,0,251.11,0,245.91)$ \\
\hline$\{$ PD4 PD5 $\}$ & 348.13 & $(0,0,0,167.53,180.60)$ \\
\hline$\{\mathrm{PD} 1 \mathrm{PD} 2 \mathrm{PD} 3\}$ & 894.50 & $(303.40,273.96,317.14,0,0)$ \\
\hline$\{P D 1$ PD2 PD4 $\}$ & 554.42 & $(225.98,190.07,0,138.37,0)$ \\
\hline$\{\mathrm{PD} 1 \mathrm{PD} 2 \mathrm{PD} 5\}$ & 731.55 & $(290.32,208.80,0,0,232.43)$ \\
\hline$\{$ PD1 PD3 PD4 $\}$ & 676.42 & $(240.92,0,265.19,170.31,0)$ \\
\hline$\{P D 1$ PD3 PD5 $\}$ & 867.98 & $(279.60,0,303.97,0,284.41)$ \\
\hline$\{\mathrm{PD} 1 \mathrm{PD} 4 \mathrm{PD} 5\}$ & 706.69 & $(249.94,0,0,190.72,266.03)$ \\
\hline$\{\mathrm{PD} 2 \mathrm{PD} 3 \mathrm{PD} 4\}$ & 638.31 & $(0,206.43,266.61,165.27,0)$ \\
\hline$\{\mathrm{PD} 2 \mathrm{PD} 3 \mathrm{PD} 5\}$ & 778.80 & $(0,212.89,318.77,0,247.14)$ \\
\hline$\{\mathrm{PD} 2 \mathrm{PD} 4 \mathrm{PD} 5\}$ & 514.60 & $(0,146.76,0,169.06,198.78)$ \\
\hline$\{$ PD3 PD4 PD5 $\}$ & 753.12 & $(0,0,281.62,198.04,273.46)$ \\
\hline$\{P D 1$ PD2 PD3 PD4 $\}$ & 1006.84 & $(284.71,250.22,325.34,146.57,0)$ \\
\hline$\{P D 1$ PD2 PD3 PD5 $\}$ & 1207.79 & $(325.58,258.86,354.03,0,269.32)$ \\
\hline$\{\mathrm{PD} 1 \mathrm{PD} 2 \mathrm{PD} 4 \mathrm{PD} 5\}$ & 940.46 & $(298.02,194.85,0,176.77,270.82)$ \\
\hline$\{\mathrm{PD} 1 \mathrm{PD} 3 \mathrm{PD} 4 \mathrm{PD} 5\}$ & 1142.90 & $(290.06,0,321.75,208.50,322.59)$ \\
\hline$\{\mathrm{PD} 2 \mathrm{PD} 3 \mathrm{PD} 4 \mathrm{PD} 5\}$ & 1038.57 & $(0,212.88,347.74,198.03,279.92)$ \\
\hline$\{\mathrm{PD} 1 \mathrm{PD} 2 \mathrm{PD} 3 \mathrm{PD} 4 \mathrm{PD} 5\}$ & 1475.68 & $(327.10,270.79,376.82,199.55,301.42)$ \\
\hline
\end{tabular}

5.6. Implication. The design of collaborative PS replenishment networks on the basis of regional partitioning and rational resource sharing propels the sustainable development of refined products' distribution and of the entire energy supply system. The CMPSRPMT optimization presents a reasonable division of refined products' distribution service zones and reduces long-distance and cross-transportation phenomena. Thus, costs are minimized, and additional benefits are offered to each PD. Effective TWA coordination and shared strategies among trucks and PSs are important characteristics of the proposed network. These improvements significantly contribute to energy and social resources and cost savings for PD operators and transportation administrations.
Cooperation among logistics facilities recently plays an important role in the optimization of distribution processes. Incorporating further transportation resource sharing can allow for more cost savings. In addition, traffic administration policies that encourage joint distribution are also a sign of political will to achieve the sustainable development of administrated areas. As one of the main development factors, refined products' distribution activities can be further organized with the coordination of TWAs and reduce the number of petrol distribution trucks. Therefore, encouraging the formation of a grand coalition is a relevant approach that can benefit not only PDs but the entire society. 


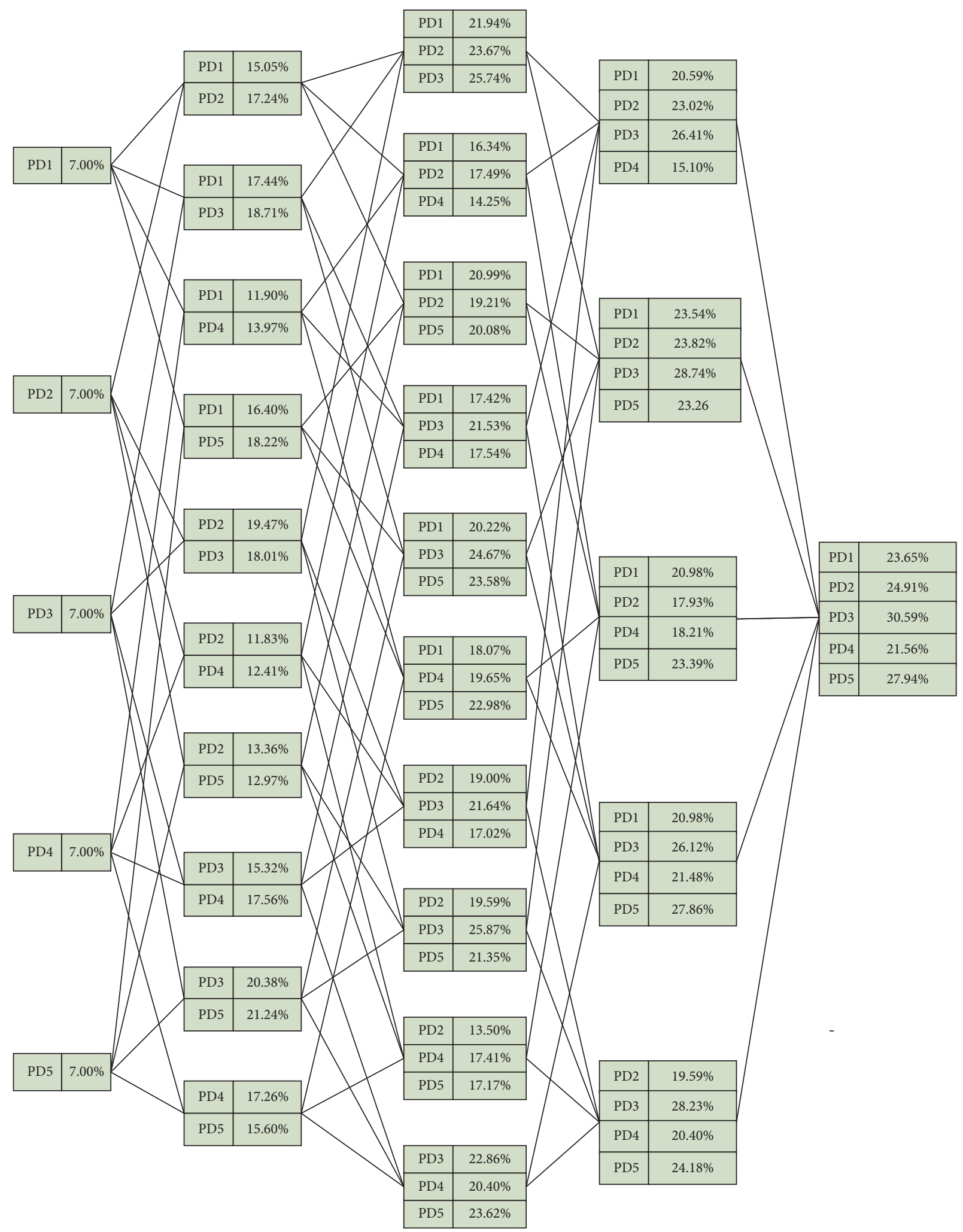

FIGURE 7: Cost reduction percentages and grand alliance formation process. 


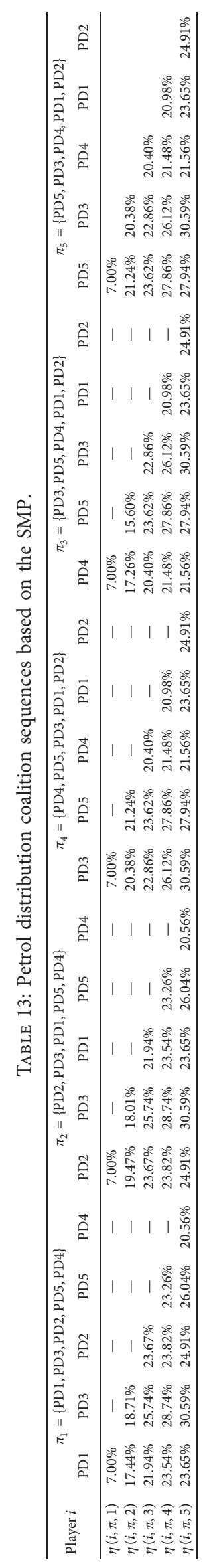


TABle 14: Optimal membership sequence based on the SMP principle.

\begin{tabular}{lccccc}
\hline \multicolumn{4}{l}{$\pi_{3}=\{\mathrm{PD} 3, \mathrm{PD} 5, \mathrm{PD} 4, \mathrm{PD} 1, \mathrm{PD} 2\}$} \\
Player $i$ & PD3 & PD5 & PD4 & PD1 & PD2 \\
\hline$\eta(i, \pi, 1)$ & $7.00 \%$ & - & - & - & - \\
$\eta(i, \pi, 2)$ & $20.38 \%$ & $21.24 \%$ & - & - & - \\
$\eta(i, \pi, 3)$ & $22.86 \%$ & $23.62 \%$ & $20.40 \%$ & - & - \\
$\eta(i, \pi, 4)$ & $26.12 \%$ & $27.86 \%$ & $21.48 \%$ & $20.98 \%$ & - \\
$\eta(i, \pi, 5)$ & $30.59 \%$ & $27.94 \%$ & $21.56 \%$ & $23.65 \%$ & $24.91 \%$ \\
\hline
\end{tabular}

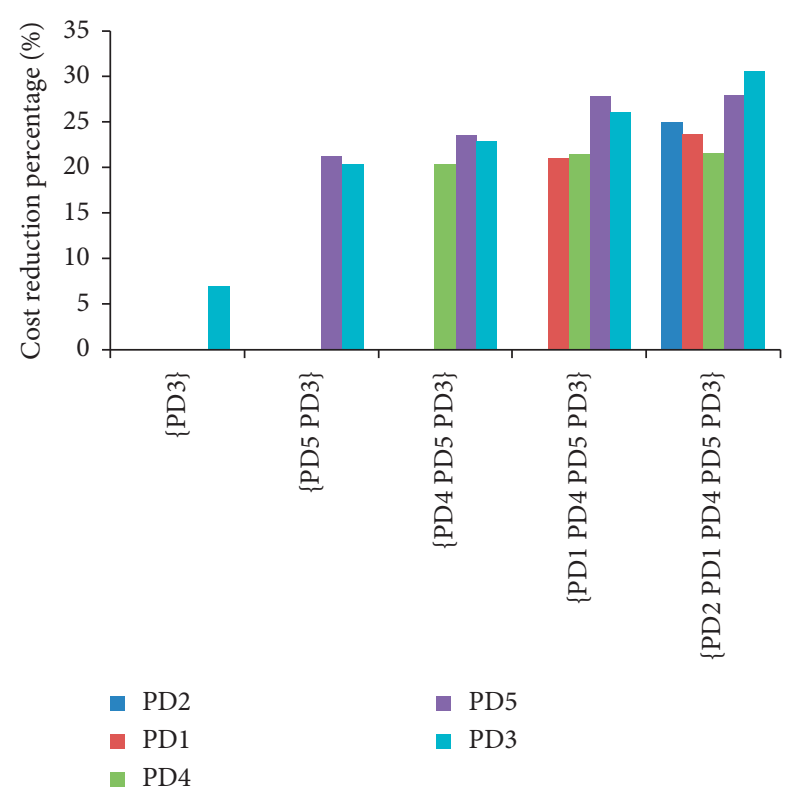

FIGURE 8: The variation of the cost reduction percentage of each petrol depot in the optimal sequence.

\section{Conclusions}

This study presents an effective method to solve the optimization of the CMPSRPMT, which improves the cooperation level of PDs and the operational optimization of refined products' distribution. The distribution and resource sharing are optimized through the regional petrol joint distribution formed by the cooperation among PDs. In the optimization process, we consider the mechanisms of PS clustering, time window coordination, and truck coutilization. The comparison of data before and after the cooperation shows that the total number of distribution trucks and the total operating costs are significantly reduced.

The optimization model considers customer clustering, TWA, and multicompartment distribution TS. As a result, the overall transportation distance and the number of trucks used are reduced. A regional petrol distribution network in Chongqing city in China is taken as an example to evaluate the effect of the proposed model and method in practice. We propose a hybrid heuristic approach based on GA and PSO and use the Shapley value method to allocate the benefits of $\mathrm{PD}$ in the cooperation. The optimal sequence of the PD joining the cooperation is found according to the SMP principle.
In summary, the study of petrol cooperative optimization is consistent with the reality. The proposed optimization method is better than that of existing research in this field. Based on the analysis, a summary of the conclusions is provided as follows. (1) Regional petrol distribution network through customer clustering, coordination of TWA, and sharing of distribution trucks can considerably shorten the distribution distance, reduce the required number of distribution trucks, and reduce the total operational costs of the network petrol distribution. (2) Optimizing the PSs served by each depot and using each other's delivery trucks when the time window allows can highly relieve the traffic stress of refined products' supply in urban areas, reduce the negative effect of the transport energy supply system, and contribute to the sustainable development of urban transportation. (3) The benefit allocation of each PD and the determination of the optimal entry sequence ensure the formation of a more cooperative distribution network and strengthen the group stability.

The results of this study point toward interesting research directions in the future. The following points can be considered. (1) This study only considers the cooperation between the PD and the PS in the process of distribution operation. Thus, the cooperation can be extended to a wider range of the transport energy supply chain. (2) This study assumes that the transport speed of petrol distribution trucks is constant, which is consistent with most of the existing joint distribution literature. Future research can consider real-time urban traffic speed analysis to achieve more realistic results. (3) In the future, the dynamic CMPSRPMT can be built by considering the product inventory of PDs and PSs.

\section{Data Availability}

The transport time, demand quantity, and service time window data used to support the findings of this study are available from the corresponding companies and administrative departments.

\section{Conflicts of Interest}

The authors declare that they have no conflicts of interest.

\section{Acknowledgments}

This research was supported by the National Nature Science Foundation of China (Grant nos. 71471024 and 71871035), the Humanity and Social Science Foundation of Ministry of Education of China (Grant nos. 18YJC630189 and 17YJA630079), and Social Science Planning Project of Chongqing of China (Grant no. 2019YBGL049).

\section{References}

[1] F. Cornillier, F. Boctor, and J. Renaud, "Heuristics for the multi-depot petrol station replenishment problem with time windows," European Journal of Operational Research, vol. 220, no. 2, pp. 361-369, 2012.

[2] https://www.xianjichina.com/special/detail-434448.html. 
[3] http://www.yjxww.com/news/gd/2019/1205/gd022846501. html.

[4] Y. Jin, "Study on optimization of distribution route of refined products," China Market, vol. 18, pp. 184-186, 2017.

[5] S. Chang, "Research on product oil joint distribution scheme," China Petroleum and Chemical Standard and Quality, vol. 11, pp. 58-59, 2018.

[6] F. Cornillier, F. F. Boctor, G. Laporte, and J. Renaud, "A heuristic for the multi-period petrol station replenishment problem," European Journal of Operational Research, vol. 191, no. 2, pp. 295-305, 2008.

[7] F. Cornillier, G. Laporte, F. F. Boctor, and J. Renaud, "The petrol station replenishment problem with time windows," Computers \& Operations Research, vol. 36, no. 3, pp. 919-935, 2009.

[8] F. F. Boctor, J. Renaud, and F. Cornillier, "Trip packing in petrol stations replenishment," Omega, vol. 39, no. 1, pp. 86-98, 2011.

[9] D. Popović, M. Vidović, and G. Radivojević, "Variable neighborhood search heuristic for the inventory routing problem in fuel delivery," Expert Systems with Applications, vol. 39, no. 18, pp. 13390-13398, 2012.

[10] M. Vidović, D. Popović, and B. Ratković, "Mixed integer and heuristics model for the inventory routing problem in fuel delivery," International Journal of Production Economics, vol. 147, pp. 593-604, 2014.

[11] S.-H. Huang, "Solving the multi-compartment capacitated location routing problem with pickup-delivery routes and stochastic demands," Computers \& Industrial Engineering, vol. 87, pp. 104-113, 2015.

[12] X. Wang, H. Zhan, and J. Zhang, "Research of oil product secondary distribution optimization based on collaborative distribution," Procedia Computer Science, vol. 60, pp. 13671376, 2015.

[13] P. Carotenuto, S. Giordani, and D. Celani, "Planning retail distribution of fuel oils," Transportation Research Procedia, vol. 27, pp. 484-491, 2017.

[14] B. Wang, Y. Liang, M. Yuan, H. Zhang, and Q. Liao, “A metaheuristic method for the multireturn-to-depot petrol truck routing problem with time windows," Petroleum Science, vol. 16, no. 3, pp. 701-712, 2019.

[15] U. Derigs, J. Gottlieb, J. Kalkoff, M. Piesche, F. Rothlauf, and U. Vogel, "Vehicle routing with compartments: applications, modelling and heuristics," OR Spectrum, vol. 33, no. 4, pp. 885-914, 2011.

[16] J. He, W. Zhang, Y. Huang, and W. Yan, "A simulation optimization method for internal trucks sharing assignment among multiple container terminals," Advanced Engineering Informatics, vol. 27, no. 4, pp. 598-614, 2013.

[17] R. Lahyani, L. C. Coelho, M. Khemakhem, G. Laporte, and F. Semet, "A multi-compartment vehicle routing problem arising in the collection of olive oil in Tunisia," Omega, vol. 51, pp. 1-10, 2015.

[18] L. C. Coelho and G. Laporte, "Classification, models and exact algorithms for multi-compartment delivery problems," European Journal of Operational Research, vol. 242, no. 3, pp. 854-864, 2015.

[19] M. Ostermeier and A. Hübner, "Vehicle selection for a multicompartment vehicle routing problem," European Journal of Operational Research, vol. 269, no. 2, pp. 682-694, 2018.

[20] B. Vahdani, F. Mansour, M. Soltani, and D. Veysmoradi, "Biobjective optimization for integrating quay crane and internal truck assignment with challenges of trucks sharing," Knowledge-Based Systems, vol. 163, pp. 675-692, 2019.
[21] M. Qi, W.-H. Lin, N. Li, and L. Miao, “A spatiotemporal partitioning approach for large-scale vehicle routing problems with time windows," Transportation Research Part E: Logistics and Transportation Review, vol. 48, no. 1, pp. 248-257, 2012.

[22] Y. Wang, X. Ma, M. Xu, L. Wang, Y. Wang, and Y. Liu, "A methodology to exploit profit allocation in logistics joint distribution network optimization," Mathematical Problems in Engineering, vol. 2015, Article ID 827021, 15 pages, 2015.

[23] Y. Wang, Y. Yuan, K. Assogba et al., "Design and profit allocation in two-echelon heterogeneous cooperative logistics network optimization," Journal of Advanced Transportation, vol. 2018, Article ID 4607493, 20 pages, 2018.

[24] Y. Wang, S. Peng, C. Xu et al., "Two-echelon logistics delivery and pickup network optimization based on integrated cooperation and transportation fleet sharing," Expert Systems With Applications, vol. 113, pp. 44-65, 2018.

[25] F. Neves-Moreira, D. Pereira da Silva, L. Guimarães, P. Amorim, and B. Almada-Lobo, "The time window assignment vehicle routing problem with product dependent deliveries," Transportation Research Part E: Logistics and Transportation Review, vol. 116, pp. 163-183, 2018.

[26] S. Martins, M. Ostermeier, P. Amorim, A. Hübner, and B. Almada-Lobo, "Product-oriented time window assignment for a multi-compartment vehicle routing problem," European Journal of Operational Research, vol. 276, no. 3, pp. 893-909, 2019.

[27] Y. Wang, S. Zhang, X. Guan et al., "Collaborative multi-depot logistics network design with time window assignment," Expert Systems With Applications, vol. 140, pp. 1-24, 2020.

[28] R. J. Kuo, F. E. Zulvia, and K. Suryadi, "Hybrid particle swarm optimization with genetic algorithm for solving capacitated vehicle routing problem with fuzzy demand - a case study on garbage collection system," Applied Mathematics and Computation, vol. 219, no. 5, pp. 2574-2588, 2012.

[29] A. Azadeh, M. H. Farahani, H. Eivazy, S. Nazari-Shirkouhi, and G. Asadipour, "A hybrid meta-heuristic algorithm for optimization of crew scheduling," Applied Soft Computing, vol. 13, no. 1, pp. 158-164, 2013.

[30] H. Zhou, M. Song, and W. Pedrycz, "A comparative study of improved GA and PSO in solving multiple traveling salesmen problem," Applied Soft Computing, vol. 64, pp. 564-580, 2018.

[31] M. Tohidifard, R. Tavakkoli-Moghaddam, F. Navazi, and M. Partovi, "A multi-depot home care routing problem with time windows and fuzzy demands solving by particle swarm optimization and genetic algorithm," International Federation of Automatic Control (IFAC), vol. 229, pp. 358-363, 2018.

[32] T. Zheng, Y. Liang, B. Wang et al., "A two-stage improved genetic algorithm-particle swarm optimization algorithm for optimizing the pressurization scheme of coal bed methane gathering networks," Journal of Cleaner Production, vol. 229, pp. 941-955, 2019.

[33] A. Alshamsi and A. Diabat, "A genetic algorithm for reverse logistics network design: a case study from the GCC," Journal of Cleaner Production, vol. 151, pp. 652-669, 2017.

[34] J. Kennedy and R. Eberhart, "Particle swarm optimization," in Proceedings of the ICNN'95-International Conference on Neural Networks, vol. 4, pp. 1942-1948, Perth, ustralia, November 1995

[35] H. Chen, A. M. K. Cheng, and Y.-W. Kuo, "Assigning realtime tasks to heterogeneous processors by applying ant colony optimization," Journal of Parallel and Distributed Computing, vol. 71, no. 1, pp. 132-142, 2011.

[36] Q. Kang, J. Wang, M. Zhou, and A. C. Ammari, "Centralized charging strategy and scheduling algorithm for electric vehicles under a battery swapping scenario," IEEE Transactions 
on Intelligent Transportation Systems, vol. 17, no. 3, pp. 659-669, 2016.

[37] H. Yuan, J. Bi, and M. Zhou, "Multiqueue scheduling of heterogeneous tasks with bounded response time in hybrid green IaaS clouds," IEEE Transactions on Industrial Informatics, vol. 15, no. 10, pp. 5404-5412, 2019.

[38] H. Yuan, J. Bi, and M. Zhou, "Spatiotemporal task scheduling for heterogeneous delay-tolerant applications in distributed green data centers," IEEE Transactions on Automation Science and Engineering, vol. 16, no. 4, pp. 1686-1697, 2019.

[39] P. Roy, G. S. Mahapatra, and K. N. Dey, "Forecasting of software reliability using neighborhood fuzzy particle swarm optimization based novel neural network," IEEE/CAA Journal of Automatica Sinica, vol. 6, no. 6, pp. 1365-1383, 2019.

[40] Y. Zhang, P. Zhou, and G. Cui, "Multi-model based PSO method for burden distribution matrix optimization with expected burden distribution output behaviors," IEEE/CAA Journal of Automatica Sinica, vol. 6, no. 6, pp. 1506-1512, 2019.

[41] T. J. Ai and V. Kachitvichyanukul, "A particle swarm optimization for the vehicle routing problem with simultaneous pickup and delivery," Computers \& Operations Research, vol. 36, no. 5, pp. 1693-1702, 2009.

[42] M. A. Mohammed, M. K. Abd Ghani, R. I. Hamed, S. A. Mostafa, M. S. Ahmad, and D. A. Ibrahim, "Solving vehicle routing problem by using improved genetic algorithm for optimal solution," Journal of Computational Science, vol. 21, pp. 255-262, 2017.

[43] L. S. Shapley, "17. A value for n-person games," Contributions to the Theory of Games (AM-28), Volume II, vol. 28, pp. 307-318, 1953.

[44] M. Frisk, M. Göthe-Lundgren, K. Jörnsten, and M. Rönnqvist, "Cost allocation in collaborative forest transportation," $\mathrm{Eu}$ ropean Journal of Operational Research, vol. 205, no. 2, pp. 448-458, 2010.

[45] S. Gao, M. Zhou, Y. Wang, J. Cheng, H. Yachi, and J. Wang, "Dendritic neuron model with effective learning algorithms for classification, approximation, and prediction," IEEE Transactions on Neural Networks and Learning Systems, vol. 30, no. 2, pp. 601-614, 2019.

[46] Z. Drezner, "Extensive experiments with hybrid genetic algorithms for the solution of the quadratic assignment problem," Computers \& Operations Research, vol. 35, no. 3, pp. 717-736, 2008.

[47] H. Katagiri, T. Hayashida, I. Nishizaki, and Q. Guo, "A hybrid algorithm based on tabu search and ant colony optimization for $k$-minimum spanning tree problems," Expert Systems with Applications, vol. 39, no. 5, pp. 5681-5686, 2012.

[48] S. Lozano, P. Moreno, B. Adenso-Díaz, and E. Algaba, "Cooperative game theory approach to allocating benefits of horizontal cooperation," European Journal of Operational Research, vol. 229, no. 2, pp. 444-452, 2013. 